\title{
Characterization of a Novel RING-Type Ubiquitin E3 Ligase GhRING2 Differentially Expressed in Cotton Fiber
}

\author{
Shiva Soma1, Chuan-Yu Hsu' ${ }^{2}$, Sukumar Saha3 ${ }^{3,4}$, Johnie N. Jenkinss,4, Din-Pow Ma ${ }^{{ }^{*}}$ \\ ${ }^{1}$ Department of Biochemistry, Molecular Biology, Entomology and Plant Pathology, Mississippi State \\ University, Mississippi State, USA \\ ${ }^{2}$ Institute for Genomics, Biocomputing \& Biotechnology, Mississippi State University, \\ Mississippi State, USA \\ ${ }^{3}$ Crop Science Research Laboratory, Agricultural Research Service, United States Department of Agriculture, \\ Mississippi State, USA \\ ${ }^{4}$ Department of Plant and Soil Sciences, Mississippi State University, Mississippi State, USA \\ Email: ${ }^{*}$ dma@bch.msstate.edu
}

Received 10 August 2014; revised 21 September 2014; accepted 24 October 2014

Copyright (C) 2014 by authors and Scientific Research Publishing Inc.

This work is licensed under the Creative Commons Attribution International License (CC BY).

http://creativecommons.org/licenses/by/4.0/

(c) (7) Open Access

\section{Abstract}

The ubiquitin-proteasome proteolysis pathway is responsible for the degradation of abnormal and short-lived proteins to regulate many important biochemical activities in eukaryotes. By employing affymetrix microarray analysis, we have identified a novel ubiquitin ligase E3 gene $\mathbf{G h}$ RING2 that is differentially expressed between two Gossypium hirsutum lines-Texas Marker-1 (TM-1) and Chromosome Substitution Line CS-B25. The CS-B25 line has chromosome 25 from $G$. barbadense substituted into TM-1. The complete nucleotide sequences of GhRING2 along with its 5'-flanking region were obtained by genomic walking. GhRING2 was highly expressed in elongating fiber, and GUS expression directed by the GhRING2 promoter was found in hypocotyls and young stems of transgenic Arabidopsis plants. Using a yeast two-hybrid assay GhRING2 was found to interact with a PROTODERMAL FACTOR1 (GhPDF1) protein. GhPDF1 was expressed preferentially in immature ovules and fiber initials, and the GhPDF1 gene had been suggested to play a role in cell fate determination and fiber development. Pull down and plasmid swap assays further confirmed the interaction between GhRING2 and GhPDF1. The expression and protein interaction data indicate that GhRING2 may be involved in the turnover of GhPDF1 and participation in the transition from initiation to elongation stages during fiber development. Our data strongly suggest that the ubiquitin-proteasome pathway may regulate cotton fiber growth and development. The nucleotide sequence data of GhRING2 in this article have been submitted to the Gen Bank Nucleotide Sequence Data Bases under the accession number BankIt 1,742,008 SeqKM 108,000.

${ }^{*}$ Corresponding author.

How to cite this paper: Soma, S., et al. (2014) Characterization of a Novel RING-Type Ubiquitin E3 Ligase GhRING2 Differentially Expressed in Cotton Fiber. American Journal of Plant Sciences, 5, 3364-3379.

http://dx.doi.org/10.4236/ajps.2014.521352 


\section{Keywords}

\section{Cotton Fiber, Gossypium hirsutum, G. barbadense, RING-Type Ubiquitin Ligase, Ubiquitination}

\section{Introduction}

Cotton is one of the most important economic crops for textile industries. Over $90 \%$ of the cotton produced worldwide is from Upland cotton (Gossypium hirsutum). Upland cotton has high percentage of lint fiber and high yield. Pima cotton (G. barbadense) produces fiber with better qualities (longer and strong fibers) but has low yield compared to Upland cotton. Cotton fiber development can be divided into four overlaping stages-intination, elongation (primary cell wall synthesis), secondary cell wall synthesis and maturation [1]. It was reported that during the onset of secondary cell wall cellulose deposition there was a steep decline in protein contents, which suggests a critical role of the proteasome proteolytic pathway in fiber development [2] [3]. Ubiquit independent proteolysis is a major pathway for the selective degradation of many abnormal and shortlived proteins in eukaryotic cells. The ubiquitin-proteasome pathway affects many processes in plant growth and development [4], including hormone signaling [5]-[10], light response, floral and seed development [11] [12], self-incompatibility, disease resistance [13], stress tolerance [14]-[18], and cell cycle progression [11]. The pathway is mediated through the covalent attachment of ubiquitin, a small protein containing 76 amino acids, to the targeted protein prior to the degradation by the $26 \mathrm{~S}$ proteasome. The ubiquitination of target proteins requires the sequential activity of three enzymes: an ubiquitin-activating enzyme (E1), an ubiquitin-conjugating enzyme (E2), and an ubiquitin ligase (E3) [19].

We previously cloned two cotton E2 genes (GhUBC1 and GhUBC2) and one E3 gene (GhRING1 encoding a RING-type ubiquitin ligase), and studied their expression in cotton fiber [20] [21]. The three genes were all expressed in fiber in a developmentally regulated manner. The E. coli over-expressed GhRING1 was found to have the ubiquitin E3 ligase activity by an in vitro reconstitution assay [21]. These data suggested that cotton fiber growth and development are regulated via protein ubiquitination and protein ubiquitination may play a role in fiber differentiation. We recently conducted Microarray experiments to compare gene expression in 10-DPA (days post anthesis) fiber between two Upland cotton lines CS-B25 and TM-1 (Texas Marker-1). CS-B25 is a chromosome substitution line, generated by replacing chromosome pairs 25 of G. hirsutum TM-1 with chromosome pairs 25 from G. barbadense double haploid 3-79 line. Using an additive-dominance model Wu et al. [22] and Saha et al. [23] showed that CS-B25 has improved fiber traits (increased fiber strength, length and decreased micronaire), indicating that the chromosome 25 from G. barbadense 3-79 may be the location containing the genes that affects economically important fiber traits. Since CS-B25 has better fiber qualities and it is nearly isogenic to the parent TM-1 for 25 pairs of chromosomes except the substituted pair of chromosome 25 from G. barbadense 3-79, a comparative analysis of gene expression in fiber between TM-1 and CS-B25 would help to identify genes associated with good fiber traits on the chromosome 25 of G. barbadense. Affymetrix microarray analysis was thus conducted by our lab to determine the difference in gene expression between TM-1 and CS-B25 fibers, and we identified four RING-type ubiquitin ligases (GhRING2-5) that are differentially expressed in 10-DPA CS-B25 fiber [24]. In this research the full length cDNA and genomic sequences of the GhRING2 gene were cloned and characterized. The expression of GhRING2 in fiber cells of TM-1 and CS-B25 at different developmental stages was determined. The ubiquitin E3 ligase activity of GhRING2 was also assayed and its target protein was subsequently identified.

\section{Materials and Methods}

\subsection{Plant Materials and Growth Conditions}

Two cotton (G. hirsutum) lines, Texas Marker-1 (TM-1) and Chromosome Substitution Line CS-B25, were planted in the field at the R. R. Foil Plant Science Research Center at Mississippi State University. Cotton flowers were tagged one day before anthesis ( $-1 \mathrm{DPA})$ to avoid cross pollination. Cotton bolls were collected at different developmental stages (5, 10, 15 and 20 DPA) in late July and August 2013, and leaf and flower were also collected. 


\subsection{Cloning and Sequencing of GhRING2 Gene}

A partial sequence of GhRING2 cDNA (360 bp) was initially obtained [24] and its sequence was used to design primers for inverse PCR genomic walking [25] to isolate the GhRING2 gene along with its 5'- and 3'-flanking regions (3040 bp). The 1905 bp containing GhRING2 and its 5'-franking region was re-amplified by PCR using Phusion high fidelity DNA polymerase (New England BioLabs), cloned into pGEM-T Easy vector, and sequenced using the Big Dye Terminator v1.1 Cycle Sequencing Kit (Applied Biosystems) on ABI PRISM 310 Genetic Analyzer.

\subsection{Homology Modeling of GhRING2 Protein}

The structure of the GhRING2 protein was constructed based on homology modeling using Modeller 9.12 [26]. The Basic Modeling protocol was used to create four Python scripts with Python programming language. All the scripts were executed using the Python GUI program [27]. Each script has its role in building GhRING2 protein structure. The first script was used to search for the structures related to GhRING2 and the second script selected the best template for GhRING2 from the structures retrieved from Protein Data Bank (PDB) having high percentage of identity. The third script aligned the amino acid sequence of GhRING2 with the template, and the fourth script was the core script that generated five GhRING2 protein models and calculated the Discrete Optimized Protein Energy (DOPE) and GA341 scores for each model. DOPE score represented the statistical possibility of atoms in the protein depart from the native structure. A protein model with minimum DOPE score will have the structure that is more comparable to the native structure. GA341 corresponded to the degree of coverage of the model structure to the template protein, EL5, an ubiquitin ligase of rice (Oryza sativa) [28] which has the highest amino acid sequence identity with the GhRING2 protein.

\subsection{Expression Analysis of GhRING2 Gene}

Total RNA was isolated from cotton flower, leaf and fiber at different developmental stages (5, 10, 15, and 20 DPA) from TM-1 and CS-B25 using a hot borate extraction method [29]. The purified RNA samples were used for synthesis of first-strand cDNA by reverse transcription using M-MLV reverse transcriptase. The transcript levels of GhRING2 in TM-1 and CS-B25 tissues (leaf, flower, and fiber at 5, 10, 15, and 20 DPA) were determined by real-time RT-PCR using the first strand cDNA samples as templates. A 178 bp GhRING2 cDNA fragment was amplified using two primers RT-R1 (5'-TTATGGTACGCCACGAATCA-3') and RT-R2 (5'CCGATTGCTCTGCCTCTATC-3') and RT-PCR master mix (SsoFast ${ }^{\mathrm{TM}}$ EvaGreen ${ }^{\circledR}$ Supermix from Bio-Rad). As a reference to analyze GhRING2 expression, the cotton polyubiquitincDNA, was amplified using two universal ubiquitin primers UBQ-F (5'-GAGTCCTCAGACACCATTGACAAC-3'), UBQ-R (5'-GTGCTCTCCTTCTGGATGTTGTAG-3'). PCR amplification was conducted with initial denaturation at $95^{\circ} \mathrm{C}$ for 3 min and followed by 45 cycles at $95^{\circ} \mathrm{C}$ for $15 \mathrm{sec}, 55^{\circ} \mathrm{C}$ for $10 \mathrm{sec}$ and $72^{\circ} \mathrm{C}$ for $15 \mathrm{sec}$ using the BIO-RAD CFX96/C1000 Real Time PCR system. A dissociation curve analysis was applied after PCR amplification to confirm the specificity of amplicon. The abundance of the GhRING2 transcript was calculated using the formula $2^{-\Delta \Delta \mathrm{CT}}$, where $\Delta \Delta \mathrm{CT}($ Cycle Threshold $)=\left(\mathrm{CT}_{\text {GhRING2 }}-\mathrm{CT}_{\text {Ubiquitin }}\right)-\left(\mathrm{CT}_{\text {Calibrator }}-\mathrm{CT}_{\text {Ubiquitin }}\right)$.

\subsection{In Vitro Auto Ubiquitination Assay of GhRING2 E3 Ligase Activity}

The ubiquitin E3 ligase activity of GhRING2 was determined by using an in vitro auto ubiquitination assay. The open reading frame (ORF) of GhRING2 was amplified by PCR using Phusion DNA polymerase and cloned into the pGEX-4t-1 vector. The recombinant plasmid pGEX-4t-1/GhRING2 was transformed into E. coli BL21 (DE3) to produce GhRING2 protein in fusion with a GST (Glutathione S-transferase) tag via IPTG induction. The GSTGhRING2 fusion protein was purified on a column packed with Glutathione Sepharose 4 Fast Flow resin (Amersham Biosciences). The in vitro ubiquitination assay was performed by mixing $25 \mu \mathrm{l}$ of reaction mixture containing $40 \mathrm{mM}$ Tris-HCl pH 7.5, 5 mM MgCl 2,2 mM DTT, 2 mM ATP, 68 ng GST-GhRING2, $7 \mu$ g ubiquitin (Sigma) with $1 \mu \mathrm{l}$ (30 - $50 \mu \mathrm{g}$ protein) of Wheat Germ Extract (Promega) which provided two enzymes, ubiquitin activating E1 enzyme and conjugating enzyme E2, for auto-ubiquitination of GhRING2. The reaction was conducted at $37^{\circ} \mathrm{C}$ for a different amount of time $(0,5,15,30,60$ and $120 \mathrm{~min})$, and reaction products were analyzed by SDS-polyacrylamide gel electrophoresis (SDS-PAGE) and then subjected to Western blot analysis using Anti-GST tag/mouse monoclonal IgG antibody with the Lumi Sensor Chemiluminecent HRP substrate kit 
(Gen Script).

\subsection{Promoter Analysis of the GhRING2 Gene}

The full length and 5' truncated promoter fragments of GhRING2, named R2GUS1 (1410 bp), R2GUS2 (910 bp) and R2GUS3 (410 bp), were PCR amplified using Phusion DNA polymerase and three primer pairs GUS-F1/ GUS-R2, GUS-F2/GUS-R2 and GUS-F3/GUS-R2, respectively. The nucleotide sequences of the four primers are GUS-F1 5'-CCCAAGCTTAAAGCATGCTTTATTGGTTC-3', GUS-F2 5'-CCCAAGCTTGCCTTTCTCTCATCTCAATC-3', GUS-F3 5'-CCCAAGCTTCTCCCACACTCGACAAATCT-3', and GUS-R2 5'-GCTCTAGAAATAGTCAGCTGGTTTTGTG-3', and restriction sites HindIII (AAGCTT) and XbaI (TCTAGA) were designed at the 5'-end of the four primers. The PCR amplified promoter fragments of GhRING2 were cloned into the binary vector pBI121 to replace cauliflower mosaic virus (CaMV) 35S promoter (835 bp) using the restriction enzymes HindIII and XbaI. The recombinant pBI121 plasmids containing GhRING2 promoter fragments upstream of the GUS reporter gene were transformed into Agrobacterium tumefaciens C58 cells by using a freeze-thaw method [30]. Arabidopsis thaliana was transformed with the C58 cells carrying the recombinant pBI121 plasmids via an Agrobacterium-mediated floral dip method [31]. The promoter activity of GhRING2 was monitored in transgenic $A$. thaliana plants using a histochemical GUS assay [32]. The seedling, leaf, flower, stem and root of transgenic $A$. thaliana plants (T2) were immersed in $1 \mathrm{ml}$ of GUS staining solution containing $100 \mathrm{mM}$ sodium phosphate $\mathrm{pH}$ 7.0, $1 \mathrm{mg} / \mathrm{ml}$ of X-Gluc (Gold BioTechnology), $0.5 \mathrm{mM}$ potassium ferricyanide, $0.5 \mathrm{mM}$ potassium ferrocyanide, $10 \mathrm{mM}$ EDTA and $0.1 \%$ Triton X-100 and incubated at $37^{\circ} \mathrm{C}$ overnight. The chlorophyll pigment was removed by extraction of the plant tissues with ethanol, and the GUS expression was observed using a Nikon SMZ1000 stereomicroscope.

\subsection{Identification of Target Protein of GhRING2}

A yeast mating method was used to identify GhRING2 interacting proteins by screening a yeast two-hybrid library with the bait plasmid pGBKT7/GhRING2. The fiber two-hybrid library was constructed by using 10-DPA fiber RNA from TM-1 with the SMART cDNA construction kit (Clontech). The fiber RNA was first reverse transcribed to form first-strand cDNA with SMART MMLV reverse transcriptase in the presence of CDSIII Primer (an oligo-dT primer). After adding SMART III-modified oligo (5'-AAGCAGTGGTATCAACGCAGAGTGGCCATTATGGCCGGG-3'), the double-stranded cDNA was generated by PCR amplification with 5' PCR Primer (5'-TTCCACCCAAGCAGTGGTATCAACGCAGAGTGG-3') and 3' PCR Primer (5'-GTATCGATGCCCACCCTCTAGAGGCCGAGGCGGCCGACA-3') and Advantage 2 Polymerase Mix (Clontech). The PCR was conducted via pre-denaturation at $95^{\circ} \mathrm{C}$ for $30 \mathrm{sec}$, following by 18 cycles at $95^{\circ} \mathrm{C}$ for $10 \mathrm{sec}$ (denaturation) and $68^{\circ} \mathrm{C}$ for $6 \mathrm{~min}$ (annealing and elongation), and a final extension at $68^{\circ} \mathrm{C}$ for $5 \mathrm{~min}$. The doublestrand cDNA PCR products were purified using the CHROMA SPIN TE-400 Column (Clontech) and the cDNAs with sizes larger than 400 bp were then used for large scale transformation of yeast Y187 cells to make the yeast two-hybrid library.

The yeast two-hybrid library cells (the haploid Y187 strain) were mated with bait cells (the haploid Y2H gold strain with pGBKT7/GhRING2) by mixing the two haploid cells and incubating them at $30^{\circ} \mathrm{C}$ in a slowly shaking incubator (50 - $60 \mathrm{rpm}$ ) for $24 \mathrm{hr}$. Mated yeast cells were washed with $50 \mathrm{ml}$ of $0.5 \times$ YPDA, re-suspended in 10 $\mathrm{ml}$ of $0.5 \times$ YPDA containing $50 \mu \mathrm{g} / \mathrm{ml}$ kanamycin, and then plated on single (-Trp or -Leu), double (-Trp and -Leu) and quadruple drop out (-Trp, -Leu, -His and -Ade) SD agar plates and incubated at $30^{\circ} \mathrm{C}$. The mating of Y187 and $\mathrm{Y} 2 \mathrm{H}$ resulted in the formation of doubly transformed diploid zygotes. The diploid zygotes can proliferate on double (-Trp and -Leu,) drop out SD medium and they can also grow on quadruple drop out (-Trp, -Leu, -His and -Ade) SD medium when the bait and prey proteins interact. Putative positive colonies that appeared on quadruple drop out SD agar plates were analyzed by yeast colony PCR using a Matchmaker Insert Check PCR Mix 2 kit (Clontech). The PCR product was purified using a QIAquick PCR purification kit (QIAGEN) and then sequenced using either the 5' PCR Primer or 3' PCR Primer.

A plasmid swap assay with pGBKT7/GhRING2 and pGADT7/GhPDF1 was employed to further test the interaction between GhRING2 and GhPDF1 that was previously identified during the screening of the yeast twohybrid library using pGADT7/GhRING2 as bait. The restriction sites of EcoRI (GAATTC) and BamHI (GGATCC) were incorporated into the 5'-end of primers Ring2-T2 (5'-CGCGAATTCATGCGCCATGGCGCGCACTATAC-3'), GDFP-1 (5'-CGCGAATTCATGGTTAATATCCGATGCTCT-3'), Ring2-T3 (5'-CGCGGATCC- 
TTAGCAAGGGTTATCATCACC-3'), and GDFP-2 (5'-CGCGGATCCTTACTGCCCAGAATTTCCCAG-3'). The ORF of GhPDF1 and GhRING2 was amplified with the primer pairs GDFP-1/GDFP-2 and Ring2-T2/Ring2-T3, respectively, using fiber cDNA as template by Phusion DNA polymerase. The GhPDF1 and GhRING2 PCR products were cloned into the EcoRI and BamHI restriction sites of pGBKT7 and pGADT7 vectors, respectively. The yeast two-hybrid system was then used to confirm the interaction between GhPDF1 and GhRING2 by cotransformation of the two recombinant plasmids into yeast $\mathrm{Y} 2 \mathrm{H}$ gold cells using the LiAc/SS carrier DNA/ PEG method [33].

\subsection{Confirmation of Interaction between GhRING2 and GhPDF1 via Pull down Assay}

The interaction between GhRING2 and GhPDF1 was conducted via a pull down assay using GST-GhRING2 and MBP (maltose binding protein)-GhPDF1 recombinant proteins. The MBP-GhPDF1 protein was prepared by cloning GhPDF1 into pMALcR1 (New England BioLabs) and overexpressed in E. coli cells. GST-tag (as a control) and GST-GhRING2 fusion proteins were respectively bound to Glutathione Sepharose 4 Fast Flow resin (Amersham Biosciences) and packed in a Poly-Prep Chromatography Column (BIO-RAD). GhPDF1-MBP (maltose binding protein) fusion protein was then loaded onto the columns and the samples were incubated at $4{ }^{\circ} \mathrm{C}$ for two hr. The resin was then washed 5 times at $4^{\circ} \mathrm{C}$ each with $20 \mathrm{ml}$ of wash buffer $(50 \mathrm{mM}$ Tris- $\mathrm{HCl} \mathrm{pH,} \mathrm{8.0,} 300$ $\mathrm{mM} \mathrm{NaCl}, 1 \%$ Triton X-100) [34]. The GST-tag and GST-GhRING2 fusion proteins were eluted from the GST resin using glutathione elution buffer $(50 \mathrm{mM}$ Tris-HCl, $\mathrm{pH}$ 8.0, $10 \mathrm{mM}$ reduced L-Glutathione, $1 \mathrm{mM}$ DTT, 1 $\mathrm{mM}$ PMSF). Eluted protein samples were subjected to SDS-PAGE and analyzed by Western blotting using mouse anti-GST tag monoclonal IgG antibody from Millipore.

\section{Results}

\subsection{Cloning and Characterization of GhRING2 Gene}

The GhRING2 gene along with its 5'-flanking promoter region (1905 bp) was cloned by using an inverse PCR genomic walking method. The nucleotide and derived amino acid sequences of GhRING2 are shown in Figure 1. The gene has no introns and encodes a protein of 132 amino acids with a predicted molecular mass of $15 \mathrm{kDa}$.

\begin{tabular}{|c|c|c|c|}
\hline & & Ring1-P1 & \\
\hline$\underset{\text { GUS }-\mathrm{F1}}{\longrightarrow} \quad \overline{\text { AAGCTT }}$ & -1501 & 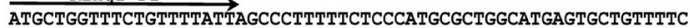 & 60 \\
\hline $\overrightarrow{\text { AAAGCATGCTTTATTGGTTCTAACTTGTTCATATITGTTATGATAACTGGAATCATTACA }}$ & -1441 & 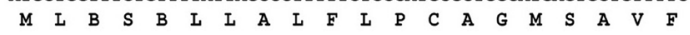 & 20 \\
\hline AAAGGTAATCCTTTAAAACGGATAAAGCCCCTTTATTATGTACCTACTAGTGGATACAGT & -1381 & ATIGTITATATCTGTCTTTTATGGTACGCCACGAATCACCGGGCTGATAATTCAGGGTCG & 120 \\
\hline TGCTTTCTTGITTTGATACTTGAAATATACCATTTATATTCACAACAGAACTTGTTTGAA & -1321 & $\begin{array}{llllllllllllllllllll}I & V & Y & I & C & L & I & W & Y & A & T & N & H & R & A & D & N & S & G & S\end{array}$ & 40 \\
\hline GTGACAAAAGTGCTATGCCATATTGATAAAATATCAAAATGTAGTTGTTTAAACTTATCT & $\begin{array}{l}-1261 \\
-1201\end{array}$ & TTATCGGTTAAGCAGGCTGGTGAGAAAGGGTTGTCCGTTTCGGAGCTTGAGAAGCTGCCC & 180 \\
\hline $\begin{array}{l}\text { TTGCATGGGACCAGATCTAATCAAATAATAAAAAGCGAGTTATACCTGTTTATATCCTTT } \\
\text { TGCTCACGTACCTTCGTTAAGATTAGGACACTCTTGTTTCAGGATCCATCTTTATAATT }\end{array}$ & $\begin{array}{l}-1201 \\
-1141\end{array}$ & 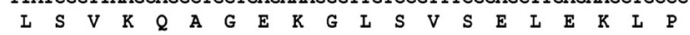 & 60 \\
\hline 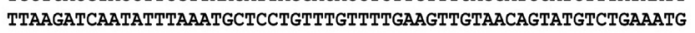 & -1081 & AAAGTTACCGGGAAGGATCTTGTGTTGGGGACTGAGTGTGCGGTTTGTCTCGATGAGATA & 240 \\
\hline GUS-F2 & & 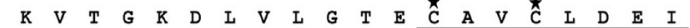 & 80 \\
\hline TTGATGTTCATCAGACTGGAAATATGTGTTTCAGGAGAAGCCTTTCTCTCATCTCAATCT & -1021 & GAGGCAGAGCAATCGGCTAGAATGGTTCCCGGTTGTAATCACGGCTTTCATTTACAATGT & 300 \\
\hline GGTAGCCAGCCACCTGTTGGGTATGGAGTATGGGGCCACAACTCAATGATTAGTTAACA & -961 & 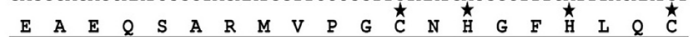 & 100 \\
\hline $\begin{array}{l}\text { TTTGTTATGTTTTTCCACGTACGTTCAAGTTGTAAGTACCACGGCGGCTCAAGCAAAGCA } \\
\text { AAACTCATTTCACATGAAAAATCAGCAGTAGCTGTTGTAAACCCTTTGCATCACGTAAGA }\end{array}$ & $\begin{array}{l}-901 \\
-841\end{array}$ & 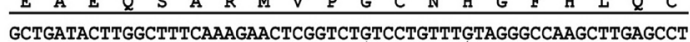 & 360 \\
\hline GAGACTTCTAACAATAATGTAAGCAAACTCAGAAACCAAAACCAAAACCTTCTTCTTATC & -781 & 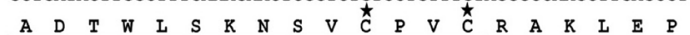 & 120 \\
\hline ATTGGGTTTAGATCCAAATGATTTATGAAAACAAACATCAGAGTCAATTTCTTTGGTTGT & -721 & Ring2-P3 & \\
\hline GTTATTTTCATAGATGCAATGATTTGTTTGGAAAGTTGTACCCAAGTTTATCCTTTCCAA & -661 & AAGTTGTTCGATCCACCTGGTGATGATAACCCTTGCTAA & 399 \\
\hline $\begin{array}{l}\text { TTGAATTTAATAACCAAGTTAGGTGGCAGGAGACCCCAATTCAATGAAGGGTCC } \overline{\mathrm{CTCCCA}} \\
\text { GUS-F3 }\end{array}$ & -601 & 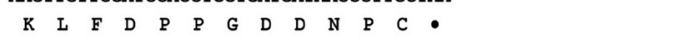 & 132 \\
\hline $\overrightarrow{\text { CACTCGACAAATCTAAAGCAACATTATACATTAGCACTAGCAAATATTATTTATATATTTT }}$ & -541 & & \\
\hline ATGTGTGTATGATTGAGTTTAATGGGCCAAACCAAATCTCTCTACCAATCATTTTTCTCT & -481 & & \\
\hline CTTCGTTITAACACAATTCTCAGTAACTGCCCATACTCCACTATCCACTCCTCTTTAATT & -421 & & \\
\hline TTTTTCTTAGCTCACAACTTTTTAACTAATAATGGTATAGGATCACATTTCTCACCCCTC & -361 & & \\
\hline ACCGTGCACAAAAAAACTCAAAGGAAAAGTACAAATAAAAGCATAACCGAAAAATCGTCA & -301 & & \\
\hline GTGCCGTTTTGATGCCTTTTGCTTGCTTGTCTGCCACGATACGCGTCATCTCTCTTCTCT & -241 & & \\
\hline ATAACTAAAACGCTAAAAATTCCATTTATTTCCCTTCCCAATATAGCCGTTACCACCCTC & -181 & & \\
\hline $\begin{array}{l}\text { TATATCTCTCACTCCAAACCCCTTCCCTTTGCCTTCCCTGGCTAGGAAACTCAACACTTC } \\
\text { GUS-R2 }\end{array}$ & -121 & & \\
\hline СССССАCAAAACCAGCTGACTATTATGCGCCATGGCGCGCACTATACCCCTCСTCCTCTC & -61 & & \\
\hline СТСТСТССTTCTCCACCACCCGCCATAAACTCCACGGCCACCGGCGGCAACCAGCACCCA & -1 & & \\
\hline
\end{tabular}

Figure 1. Nucleotide and derived amino acid sequences of cotton GhRING2 Gene. The promoter region and ORF were designated from -1 to $-1506 \mathrm{nt}$ and 1 to 399 nt. The RING domain of GhRING2 is underlined and the eight conserved Cys and His residues in the domain are marked with stars. The primer pairs GUS-F1/GUS-R2, GUS-F2/GUS-R2 and GUS-F3/GUSR2 were used to amplify the promoter fragments R2GUS1, R2GUS2 and R2GUS3, respectively, for GUS assays. The primers Ring2-P1 and Ring2-P3 were used to amplify the GhRING2 ORF for GhRING2 GST fusion protein expression. The RING H2 domain was underlined and the conserved six Cysteine and two Histidine residues within the domain were marked with stars. 
The GhRING2 protein contains a RING H2 domain with conserved cysteine and histidine residues and is classified as a $\mathrm{C}_{3} \mathrm{H}_{2} \mathrm{C}_{3}$ (RING-H2) type protein. The six cysteine and two histidine residues in the H2 domain are involved in Zn binding. A protein Blast (blastp) search was performed to find RING proteins homologous to GhRING2 from plants, and eleven closly related ubiquitin E3 ligases with their amino acid sequences, including Theobroma cacao (TcRING), Fragaria vesca (FvRING), Ricinus communis (RcRING), Populus trichocarpa (PtRING), Solanum lycopersicum (LeRING), Vitis vinifera (VvRING), Prunus persica (PpRING), Cicer arietinum (CaRING), Medicago truncatula (MtRING), Arabidopsis lyrata (AlRING) and Arabidopsis thaliana (AtRING) were retrived. A multiple sequence alignment was performed for these eleven sequenceses along with GhRING2 using the program ClustalW2 from EMBL-EBI. Sequence alignment results indicated that 6 cysteine and 2 histidine residues of the $\mathrm{C}_{3} \mathrm{H}_{2} \mathrm{C}_{3}$ (RING-H2) motif were highly conserved among all the 12 plant RING finger proteins (Figure 2), suggesting that the RING finger domain is evolutionarily conserved in plant ubiquitin ligases. A phylogenetic analysis was conducted using the amino acid sequences of the RING protiens from the twelve plants, and a phylogenetic tree was constructed and shown in Figure 3. The RING proteins TcRING from Theobroma cacao and PtRING from Populus trichocarpa are the two most closely related E3 ubiquitin ligases to the GhRING2 protein.

Structural analysis of the GhRING2 protein was performed by finding the closest protein homologue with a solved structure. A BLAST search of Protein Data Bank (PDB) indicates that amino acid sequence of GhRING2 has the highest identity to EL5, an ubiquitin ligase of rice (Oryza sativa) [28]. The RING H2 domain of GhRING2 has 57\% amino acid sequence identity with EL5 and the structure of GhRING2 modeled using Modeller 9.12 is shown in Figure 4. The hydrophobicity of GhRING2 was analyzed using the tool ProtScale [35] from the ExPASy Server. The hydrophobicity plot (data not shown) indicated that GhRING2 has both hydrophilic and hydrophobic amino acids and the N-terminal residues have higher hydrophobicity than C-terminal residues. The ProtScale analysis suggests that GhRING2 is a trans-membrane protein with hydrophobic N-terminal [36].

Cotton (Gossypium hirsutum) is a disomic tetraploid with A- and D-genomes obtained from diploid ancestors. The GhRING2 homologous gene was amplified by PCR from both A2 (G. arboreum) and D5 (G. raimondii) genomes using the forward primer Ring2-P2 (5'-CGCGGATCCATGCTGGTTTCTGTTTTAT-3') and reverse primer Ring2-P3 (5'-CGCGAATTCTTAGCAAGGGTTATCATCACC-3'). Sequence analysis of the PCR

\begin{tabular}{|c|c|c|c|}
\hline TCRING & ----------MRHGGHYTPPPLLSPSPSPALNSTTTAGSHHPMLVSVFLALFLPCAGM 48 & TCRING & TECAVCLDEIEAEQPARVVPGCNBGFHLOCADTWLSKHSVGCVVCRAKIEPD-----QLFD 157 \\
\hline FVRING & --1---MLFSIFLALFLPCVGM 16 & FVRING & TECAVCLDEIE PEOPARWVGCNHGFHLCADTWLSKNSCCEVCRAKLOPQ-----OTYA 125 \\
\hline RCRING & MHNGVQYAPLTPHPPLLISPSSPPASLSIPPPPPITAAAAANONMLLSVFLALFLPCVGM 60 & RcRING & TECAVCLDEIESEQPARLVPGCNBGFHLECADTWLSNHSVCEVCRAKLDS------QFFN 168 \\
\hline PtRING & --1-1 & PtRING & TECAVCLDDIESE QVARMVPGCNBGFHLECADTWLTKRPVCEVCRAKLDA------QLFS 122 \\
\hline LERING & 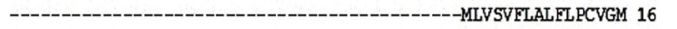 & LeRING & NDCAVCLDEIENEQIARVVPGCNBGFHLECADTWL SKNPICEVCRTKLEP------EFFN 127 \\
\hline VVRTNG & - & VvRING & AECAVCLDEIE SDAPARLI PGCNHGFHLOCADTWLSKHSVCPLCRAILAP------E FFN 123 \\
\hline PpRING & 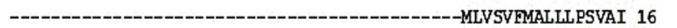 & PpRING & TECAVCLEEIE GE QVARLVPGCNHAFHLLCADTWLSKHSFCPVCRAKLQLHQDLPQSSVT 131 \\
\hline CaRING & --10--MLDAVLLALFLPCLGM 16 & CaRING & PECAVCLDEIGLDQSVRVI PGCNHSFHLECADTWLSRNPLCEVCRAKIDA------NFFI 126 \\
\hline MtRING & -10--MLDTVLALFLPCLGM 16 & MtRING & TECAVCLDDTVDEQPARLL PGCNHAFHLCADTWLSKHPMCPLCRAKLDP------QSLN 122 \\
\hline AIRTNG & - & AlRING & TECAVCLEDIE SGQSGRLVPGCNBGFHRLCADTWL SNHTVGCVCRAELAP------NIPQ 155 \\
\hline AtRING & -------------MHYTRISPALVPLSPTAAAESSGGGMIATVRALLLPCVGM 43 & AtRING & TECAVCLEDIESGQSTRLVPGCNHGFHOLCADTWLSNHTVGEVGRAELAP------NLPQ 155 \\
\hline GhRING2 & -MLVVLLALFLPCAGM 16 & GhRING2 & 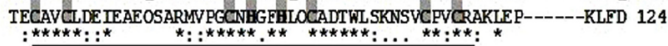 \\
\hline TCRING & SAVFTVYICLLWYATNYRTG---NSGSLAIROVAEKGLSVSELEKLPKVTGKELVLG--- 102 & TcRING & AS-----DENPC 164 \\
\hline FvRING & SAVEVVYICLLWFASNSRSA---VARQLPVKHVSEKGLSASDLEKLPKTSGKELIRG--- 70 & FVRING & SS-----DDNPC 132 \\
\hline RCRING & SAIFLTYICLLWYAANHHHH---SE IVTPVKPSAEKGLSASDLEKLPKMTGKELILG--- 114 & RCRING & AS-----TDNPC 175 \\
\hline PtRING & SAVETVYICLLWYTANNQPE---IR--LPVKTVTEKGLSSSELEKLPKVTGKELVLG--- 68 & PtRING & TPPPPAQENNTC 134 \\
\hline LeRING & SAVELVYICLLWYAAAYQSAGPGAENYHSOKTNOELGLSAAQLDKLPKITGNELLMG--- 73 & LERING & PP-----ESNPC 134 \\
\hline VVRING & SWVVVYICLLWYSALGQ-Q---PELPAPVKPESEKGLSASDLDKLPKLAGKDLVYG--- 69 & VvRING & TS------ENPC 129 \\
\hline PpRING & SAVFVVYICLLWYATNNOEQ---PEVRLPVKQVSOKGLSASELDKLPKITGKELTTER-- 71 & PpRING & CS------ENPC 137 \\
\hline CaRING & SAIFI TYMCLLWYATTHRPR-NNINAIQPVKRVTDNGLSPSDLOKLPTITGKDLLAA--- 72 & CaRING & ASSS----LNSC 134 \\
\hline MtRING & SAI FVVYMCLL YATTRHRSD-SNP-----PLKPVTEKGLSPLDLEKLPKLTGKELLAP--- 68 & MtRING & SES-------PC 127 \\
\hline AIRING & CIVELTYLFLLWCSTRRRIER--IRFAEPVKPVTGKGLSVLELEKIPKLTGKELAIIARS 101 & AlRING & CNE----NQSPC 163 \\
\hline AtRING & CIVELIYLFLLWCSTRRRIER--IREAEPVKRYTGKGLSVLELEKIPKLTGRELAVIARS 101 & AtRING & CNE----NQSPC 163 \\
\hline \multirow[t]{2}{*}{ GhRING2 } & SAVFIVYICLLWYATNHRAD---NSGSLSVKOAGEKGLSVSELEKLPKVTGKDLVLG--- 70 & GhRING2 & PPG----DDNPC 132 \\
\hline & 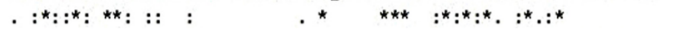 & & \\
\hline
\end{tabular}

Figure 2. Comparison of amino acid sequences of twelve plant RING proteins. Multiple sequence alignment was performed using the Clustal method. The RING proteins are from: Gossypium hirsutum (GhRING2), Theobroma cacao (TcRING) with GI: 508723217, Fragaria vesca (FvRING) with GI: 470110114, Ricinus communis (RcRING) with GI: 255539054, Populus trichocarpa (PtRING) with GI: 224083141, Solanum lycopersicum (LeRING) with GI: 460385383, Vitis vinifera (VvRING) with GI: 225459738, Prunus persica (PpRING) with GI: 462422985, Cicer arietinum (CaRING) with GI: 502126436, Medicago truncatula (MtRING) with GI: 357467061, Arabidopsis lyrata (AlRING) with GI: 297790413, Arabidopsis thaliana (AtRING) with GI: 15238323. Dashed line represents the gaps introduced to increase the identities. A colon (:) and a period (.) corresponds to homologous and non-homologous substitutions of amino acids respectively. Asterisks (") represents the identical amino acids conserved in all sequences. RING domain is underlined and the eight conserved Cys and His residues in $\mathrm{C}_{3} \mathrm{H}_{2} \mathrm{C}_{3}$ (RING-H2) motif are highlighted using grey color. 


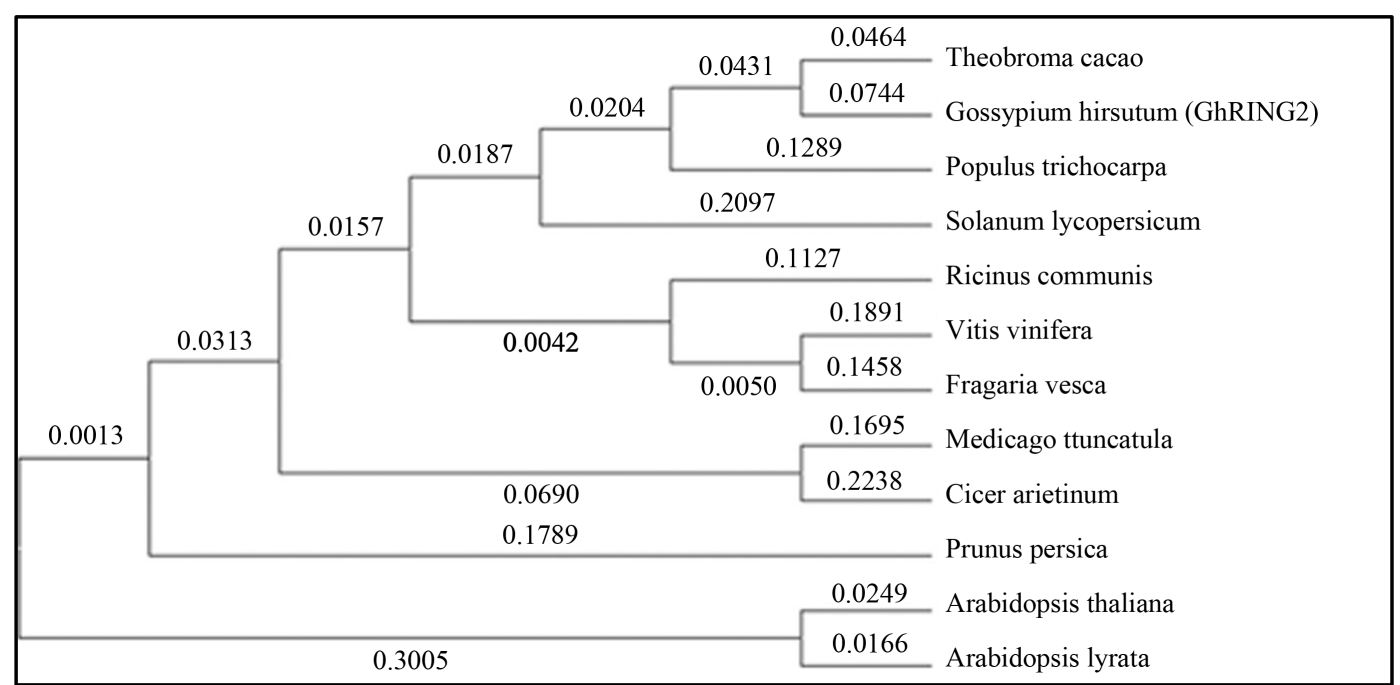

Figure 3. Phylogenetic analysis of E3 ubiquitin ligases from Gossypium hirsutum and 11 other plants. The evolutionary history of GhRING2 was inferred using the neighbor-Joining method [47]. Using the Clustal method [48] the phylogenetic tree was constructed based on amino acid sequences of E3 ubiquitin ligase gene from Gossypium hirsutum (GhRING2) and 11 other plants (Theobroma cacao with GI: 508723217, Fragaria vesca with GI: 470110114, Ricinus communis with GI: 255539054, Populus trichocarpa with GI: 224083141, Solanum lycopersicum with GI: 460385383, Vitis vinifera with GI: 225459738, Prunus persica with GI: 462422985, Cicer arietinum with GI: 502126436, Medicago truncatula with GI: 357467061, Arabidopsis lyrata with GI: 297790413, Arabidopsis thaliana with GI: 15238323). The evolutionary distances were calculated by MEGA5 using the Poisson correction method [49]. The branch length with numbers represents the evolutionary distance between the homologous genes.

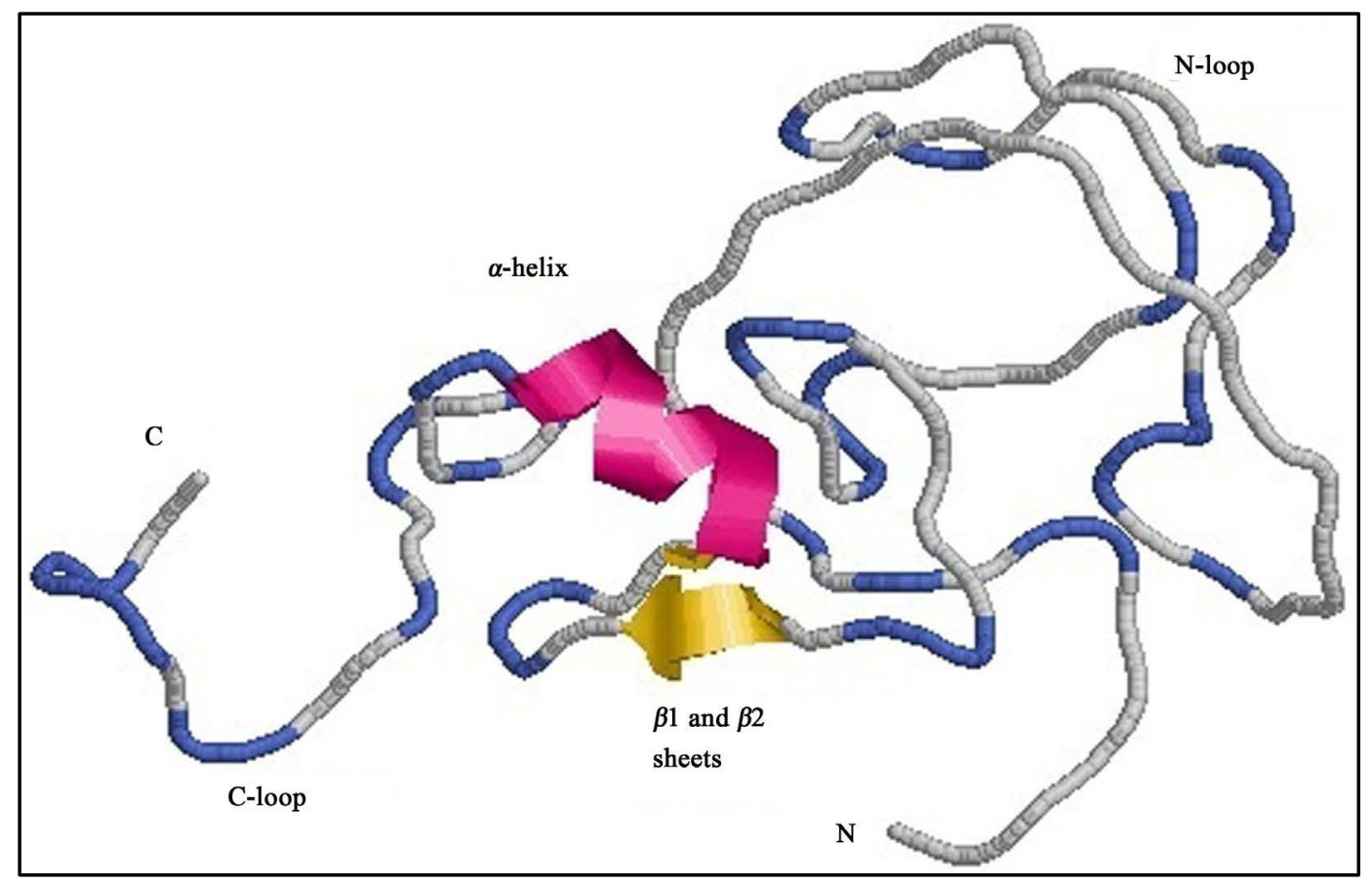

Figure 4. The structure of the GhRING2 protein. The RING-H2 domain of GhRING2 contains two beta sheets $(\beta 1$ and $\beta 2$ ) and one alpha helix $(\alpha 1)$ connected to $\mathrm{N}$ and $\mathrm{C}$ terminal loops.

products revealed that the homologous GhRING2 genes from A2- and D5-genomes have only two base pair difference in the nucleotide sequence, which changes amino acid residues at two positions (data not shown). The aa 
residues at positions 41 and 110 in the A2-genome protein are Leucine and Valine, whereas in the D5-genome they are Serine and Isoleucine. The sequence data also suggest that GhRING2 is present in the A-genome of $G$. hirsutum.

\subsection{Expression Analysis of GhRING2 Gene}

The transcript levels of GhRING2 in TM-1 and CS-B25 tissues (leaf, flower and fiber at different developmental stages) were determined by Real-Time RT-PCR amplification of a 178 bp cDNA fragment of the GhRING2 gene. The Real Time RT-PCR results showed that the transcript level of GhRING2 in the leaf tissue of TM1 and CS-B25 was almost identical (Figure 5). In contrast, GhRING2 was expressed in higher levels in the flower of TM-1 than CS-B25. The transcript levels of GhRING2 in fiber increased at the late elongation and secondary wall synthesis stages in both TM-1 and CS-B25 (Figure 5). The GhRING2 mRNA reached a maximal level in 20-DPA fiber, but the transcript level in TM1 was higher than that in CS-B25. Interestingly, the GhRING2 fiber mRNA in TM-1 was at a high level at 10-DPA, declined in 15-DPA fiber, and then increased to a maximum at 20-DPA.

\subsection{Assay of GhRING2 E3 Ligase Activity}

The open reading frame (ORF) of GhRING2 was cloned into the pGEX-4t-1 vector to express the GhRING2 protein in fuse with the glutathione S-transferase (GST) protein in E. coli BL21 (DE3) cells. A 58 kDa GSTGhRING2 fusion protein was expressed (data not shown), purified using GST-resin affinity chromatography, and used in the assay of GhRING2 ligase activity by employing an auto-ubiquitination assay. The GST-GhRING2 protein was mixed with wheat germ lysate, ATP, and ubiquitin and incubated at $37^{\circ} \mathrm{C}$ for $0-120 \mathrm{~min}$. The reaction mixtures were then fractionated on a SDS-PAGE gel and subjected to Western blot analysis using anti-GST antibody. The results of Western analysis showed that high molecular weight polyubiquitinated GhRING2 proteins were formed (Figure 6), indicating that GhRING2 had the ubiquitin E3 ligase activity. The higher molecular weight polyubiquitinated GhRING2 proteins were progressively accumulated with the increase in incubation time from 0 - 120 min (Figure 6).

\subsection{Identification of Target Proteins of GhRING2}

Y2H gold yeast cells containing pGBKT7/GhRING2 were used as bait to identify the target proteins of Gh-

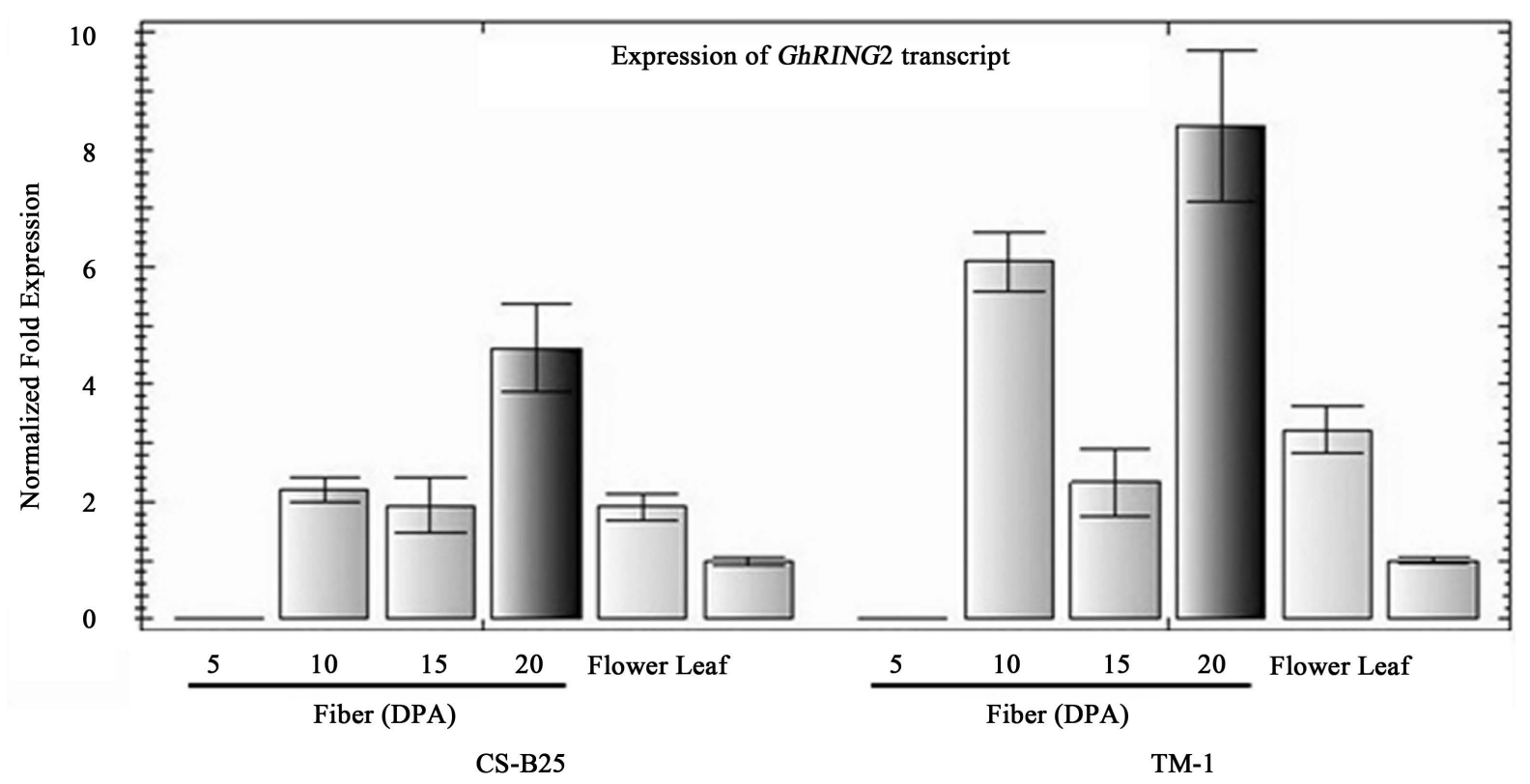

Figure 5. Comparison of relative expression of GhRING2 between CS-B25 and TM1 in different tissues of leaf, flower and fiber at different developmental stages (5, 10, 15 and 20-DPA). Triple replication of tissue samples were used in expression analysis. The error bars were presented as standard deviation (SD). 


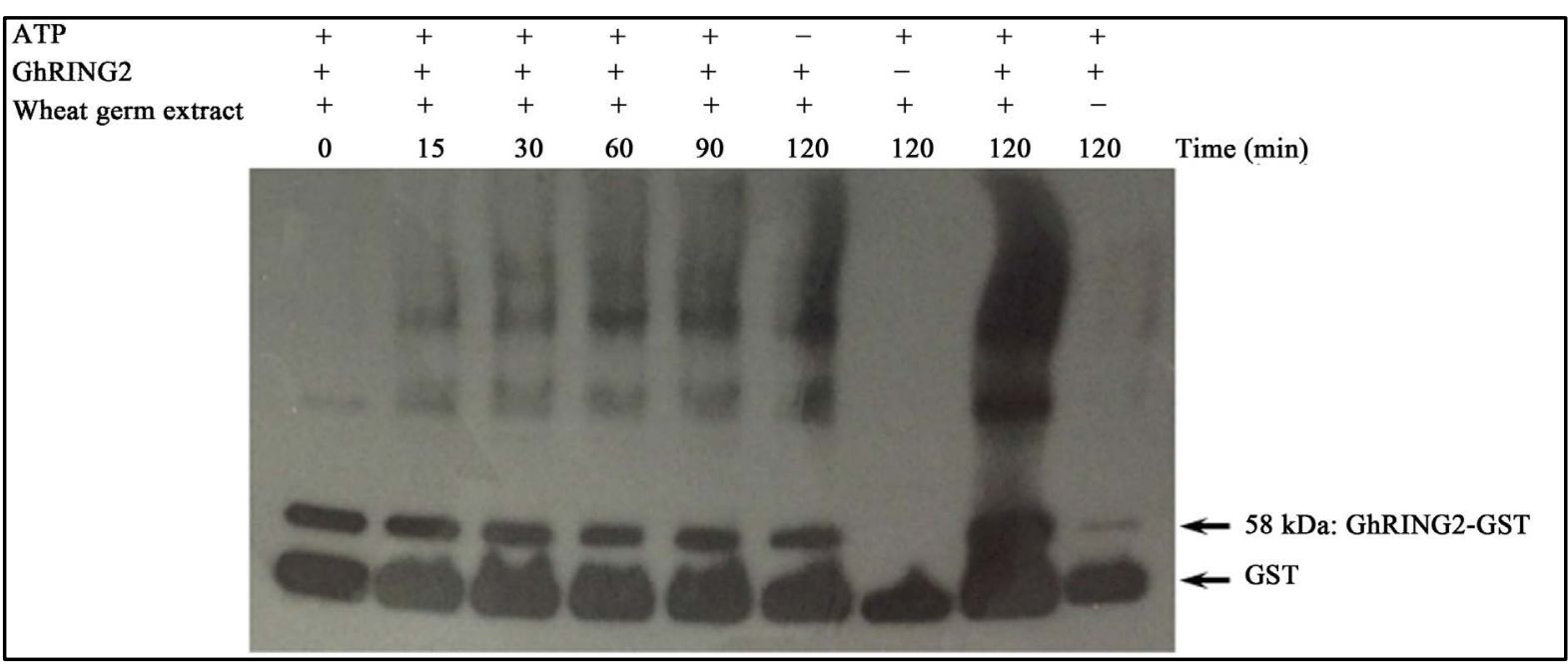

Figure 6. In vitro auto-ubiquitination assay of GhRING2 E3 ligase activity using wheat germ extract. Anti-GST antibody (1 to 5000 dilutions) was used as the probe in Western analysis.

RING2 from a yeast two-hybrid library constructed in the haploid Y187 strain. A PROTODERMAL FACTOR1 (GhPDF1) protein and the 7- $\beta$-like subunit of 20S protease were identified as the target proteins of GhRING2. The GhPDF-1 gene was subsequently amplified by PCR with primers GDFP-1 and GDFP-2 (primer sequences were designed from the GbPDF-1 gene sequence of G. barbadense) and sequenced. The GhPDF-1 gene encodes a protein containing 494 amino acids, which was previously described [37]. The interaction between GhRING2 and GhPDF1 was further confirmed using the yeast two-hybrid system via swap of the two plasmids pGADT7 and pGBKT7 to clone GhRING2 and GhPDF1. Transformed Yeast Y2H Gold cells containing pGBKT7/ GhPDF1 and pGADT7/GhRING2 plasmids were able to grow on the quadruple dropout synthetic medium plates (Figure 7(B), Section 2; Figure 7(C), Section 2) and express the alpha galactosidase activity (Figure 7(C), Section 2).

\subsection{Confirmation of Interaction between GhRING2 and GhPDF1 via in Vitro Pull down Assays}

An in vitro pull down assay was performed to confirm the protein-protein interaction between GhRING2 and GhPDF1. The open reading frame (ORF) of GhPDF1 was cloned into the pMAL-c5X vector (New England Bio Labs) to express the GhPDF1 protein in fuse with maltose-binding protein (MBP), and the expressed MBPGhPDF1 fusion protein was purified using amylose affinity chromatography (amylose resin from New England BioLabs) and analyzed by SDS-PAGE (Figure 8(A)). Four distinct protein bands were observed in the purified MBP-GhPDF1 fusion protein (Figure 8(B), lane 3), and the highest molecular weight band (top band) represents the intact MBP-GhPDF1 fusion protein $(107 \mathrm{kDa})$ and the lowest molecular weight band is MBP (52 $\mathrm{kDa}$ ). The two middle bands between MBP and MBP-GhPDF1 may represent partially degraded MBP-GhPDF1 fusion proteins. The presence of MBP and MBP-GhPDF1 proteins was further confirmed by Western analysis using anti-MBP rabbit antiserum (New England BioLabs) antibody as the probe (Figure 8(C)).

The in vitro pull down assay was conducted by incubating MBP and GhPDF1-MBP fusion proteins with GST-tag and GST-GhRING2 fusion proteins pre-bound to Glutathione Sepharose 4 Fast Flow resin (Amersham Biosciences) at $4^{\circ} \mathrm{C}$ for two hr. The resin-bound GST-tag incubated with GhPDF1-MBP fusion was served as a negative control. The presence of GhPDF1-MBP fusion protein associated with GST-GhRING2 in the fraction eluted with reduced glutathione was used to demonstrate protein-protein interaction between GhRING2 and GhPDF1 proteins. The pull down assays via SDS-PAGE (Figure 9(A)) and Western (Figure 9(B)) analyses clearly demonstrated that GhRING2 interacted with GhPDF1. The co-purification of MBP-GhPDF1 fusion protein with GST-GhRING2 fusion protein was observed in the second elution from the resin bound GSTGhRING2 incubated with GhPDF1-MBP (Figure 9(A), lane 9; Figure 9(B), lanes 5 and 6), but not the resin bound GST-tag incubated with GhPDF1-MBP (Figure 9(A), lanes 6 and 8; Figure 9(B), lanes 3 and 4). The enrichment of the intact MBP-GhPDF1 fusion protein (the highest molecular weight band) in the second elution- 

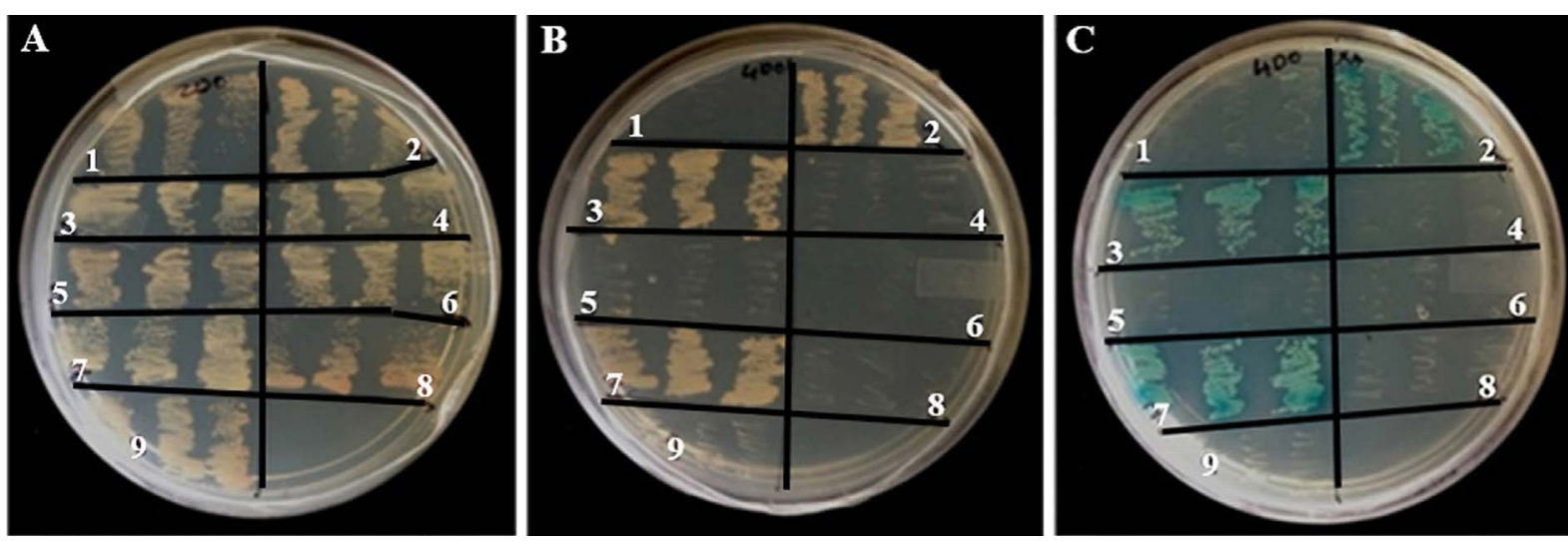

Figure 7. Testing interaction of GhRING2 and GhPDF1. Yeast Y2H Gold cells were co-transformed with (1) pGADT7GhRING2/pGBKT7; (2) pGADT7-GhRING2/pGBKT7-GhPDF1; (3) pGADT7-GhPDF1/pGBKT7-GhRING2; (4) pGADT7-GhPDF1/pGBKT7; (5) pGADT7/pGBKT7-GhRING2; (6) pGADT7/pGBKT7-GhPDF1; (7) pGADT7-T/pGBKT7-53; (8) pGADT7-GhRING2/pGBKT7-53; and (9) pGADT7/pGBKT7. (A)-(C) represent plates containing double drop out (-Trp and -Leu), quadruple drop out (-Trp, -Leu, -His and -Ade), and quadruple drop out with alpha-gal minimal synthetic defined media, respectively. The blue color in the (C) plate represents alpha-galactosidase activity which degrades the substrate alphagal into blue color product.

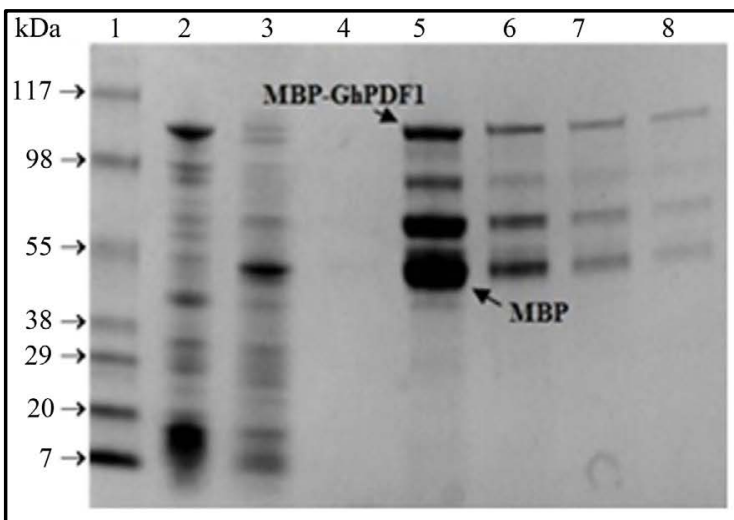

(A)

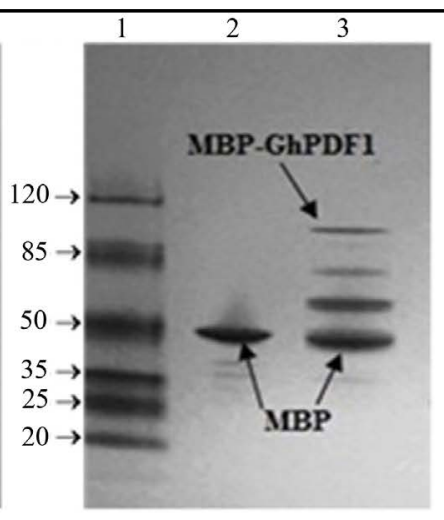

(B)

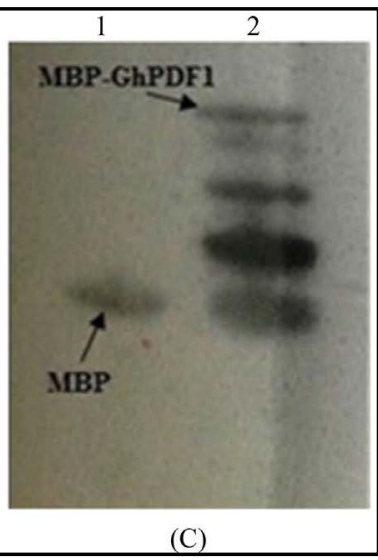

(C)

Figure 8. Analysis of purified MBP and MBP-GhPDF1 fusion proteins. Protein fractions of expressed MBP-GhPDF1 were analyzed by SDS-PAGE (A). Lanes 1, 2, 3 and 4 in A represent protein marker (individual band represented in kDa), cell pellet, supernatant and wash, respectively; lanes 5, 6, 7, and 8 are MBP-GhPDF1 elutions in four tubes. The purified MBP and MBP-GhPDF1 proteins were analyzed by SDS-PAGE (B) and Western analyses (C). Lanes 1, 2 and 3 in B are protein marker (band size represented in $\mathrm{kDa}$ ), MBP (52 kDa) and GhPDF1-MBP fusion protein (107 kDa), respectively. Image C represent Western blotting results using anti-MBP rabbit antiserum antibody (New England BioLabs) as the probe; lanes 1 and 2 in $\mathrm{C}$ are MBP and GhPDF1-MBP fusion proteins, respectively.

(Figure 9(B), lane 6) indicated that the intact GhPDF1 fusion protein was more efficient in binding to GhRING2 than partially degraded GhPDF1-MBP proteins (the two smaller protein bands).

\subsection{Promoter Analysis of GhRING2}

A GUS reporter system was utilized to analyze the GhRING2 promoter using transgenic Arabidopsis plants containing the full-length promoter R2GUS1 and 5'-truncated promoter fragments R2GUS2 and R3GUS3. The GUS system allows the detection of tissue-specific localization expression of the reporter $\beta$-glucuronidase under the control of the GhRING2 promoter.

The GUS expression was detected in the hypocotyls of transgenic Arabidopsis thaliana seedlings containing the promoter fragments R2GUS1 (Figure 10(A)) and R2GUS2 (Figure 10(B)). No GUS activity, however, was detected in transgenic seedlings containing the short promoter fragment R2GUS3 (Figure 10(C)). GUS expression was also not detected in the roots of transgenic seedlings containing the full length and 5' truncated promo- 


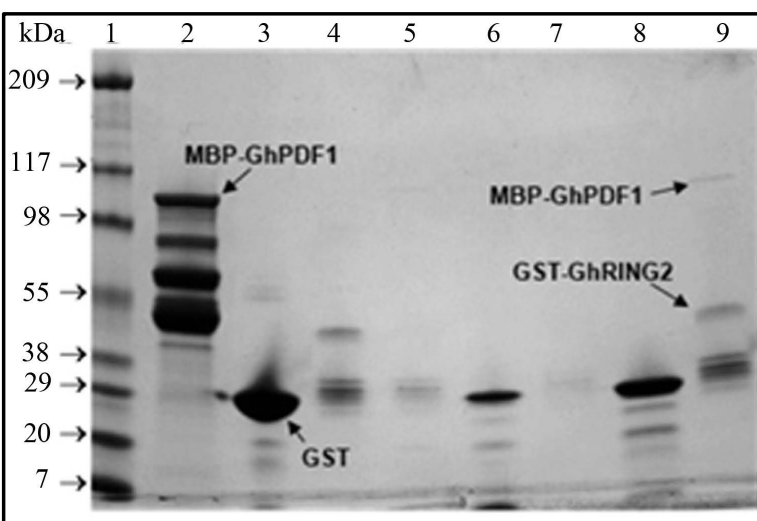

(A)

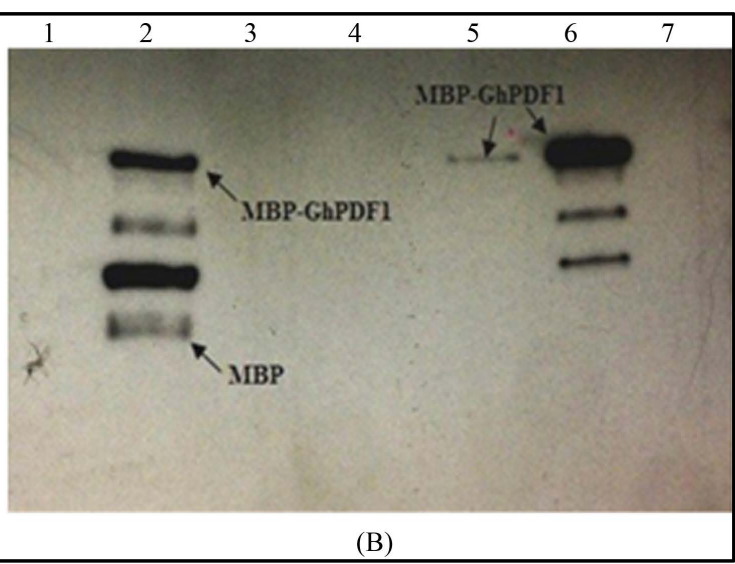

(B)

Figure 9. Pull down assays of interaction between GhRING2 and GhPDF1 via SDS-PAGE (A) and Western analyses (B). Lanes 1, 2, 3 and 4 in SDS-PAGE gel (Figure (A)) contain protein marker (band size represented in kDa), purified MBPGhPDF1 fusion protein, GST-tag and GST-GhRING2 fusion protein, respectively; lanes 5, 9 and 7 are three elutions in order from the resin bound GST-GhRING2 incubated with GhPDF1-MBP; and lanes 6 and 8 are two elutions from the resin bound GST-tag incubated with GhPDF1-MBP. The protein samples for Western analysis (Figure (B)) are purified GST-GhRING2 (lane 1), MBP-GhPDF1 (lane 2), two elutions from the resin bound GST-tag incubated with GhPDF1-MBP (lanes 3 and 4), three elutions in order from the resin bound GST-GhRING2 incubated with GhPDF1-MBP (lanes 5, 6 and 7). Anti-MBP rabbit antiserum (New England BioLabs) antibody (1:1000 dilution) was used as the probe.

ter fragments (data not shown). The GUS expression results suggested that the promoter regions (R2GUS1 and R2GUS2) from -607 to -1506 nt are crucial for GhRING2 expression during hypocotyl development. Because of rapid elongation of cells in hypocotyl tissue, the GhRING2 gene might have a functional role in cotton fiber cell elongation. The GUS activity was also detected in the young stem of five-week-old transgenic Arabidopsis plants containing the full length and 5' truncated promoter fragments R2GUS1 (Figure 10(E)), R2GUS2 (Figure 10(F)) and R2GUS3 (Figure 10(G)), respectively. No GUS activity was detected in the stem of the wild type Arabidopsis thaliana plants (Figure 10(H)). The cross section of young and mature stems of five week old transgenic Arabidopsis plants containing the full length R2GUS1 and 5' truncated promoter fragments R2GUS2 and R2GUS3 were also analyzed to determine the localization of GUS activity. It was observed that GUS activity was localized to xylem and cambium cells of young stems (Figures 10(I)-(K) and Figure 10(M)) but not in mature stems (Figure 10(L) and Figure 10(N)) of the transgenic plants.

\section{Discussion}

\subsection{Protein Ubiquitination and Fiber Development}

The ubiquitin proteasome pathway plays an important role in all aspects of plant growth and development. The differential expression of two E2 genes, GhUBC1 and GhUBC2 [20], and the GhRING1 [21] and GhRING2 genes in cotton fiber cells strongly suggests that cotton fiber growth and development may be regulated by protein ubiquitination. Hovav et al. [38] and Al-Ghazi et al. [39] have shown that several hundred genes involved in the ubiquitin-mediated protein degradation pathway, including genes for the subunits of proteasome, E2, SCF F-box proteins, and RING-type ubiquitin E3 ligases were highly up-regulated in fiber at the elongation and the secondary cell wall synthesis stages. These observations further support that protein ubiquitination may play a role in fiber differentiation and development.

The expression of the GhRING2 gene in TM-1 fiber displayed two phases, with maximal expression at 10 and 20 DPA. This observation indicates that GhRING2 expression was possibly regulated by at least two transcriptional factors. It also strongly suggests that GhRING2 may be involved in fiber development at late elongation and secondary wall synthesis stages. The length of cotton fiber depends on the rate and duration of elongation stage, which in turn depends on the number of days before elongation ceases [40]. Lower expression of GhRING2 in CS-B25 than TM-1 at 10 and 20 DPA might reduce the protein that positively regulates the elongation and secondary wall synthesis stages. Therefore, the CS-B25 line might have longer duration in these stages and subsequently resulted in high fiber length and strength. This hypothesis based on the expression data 

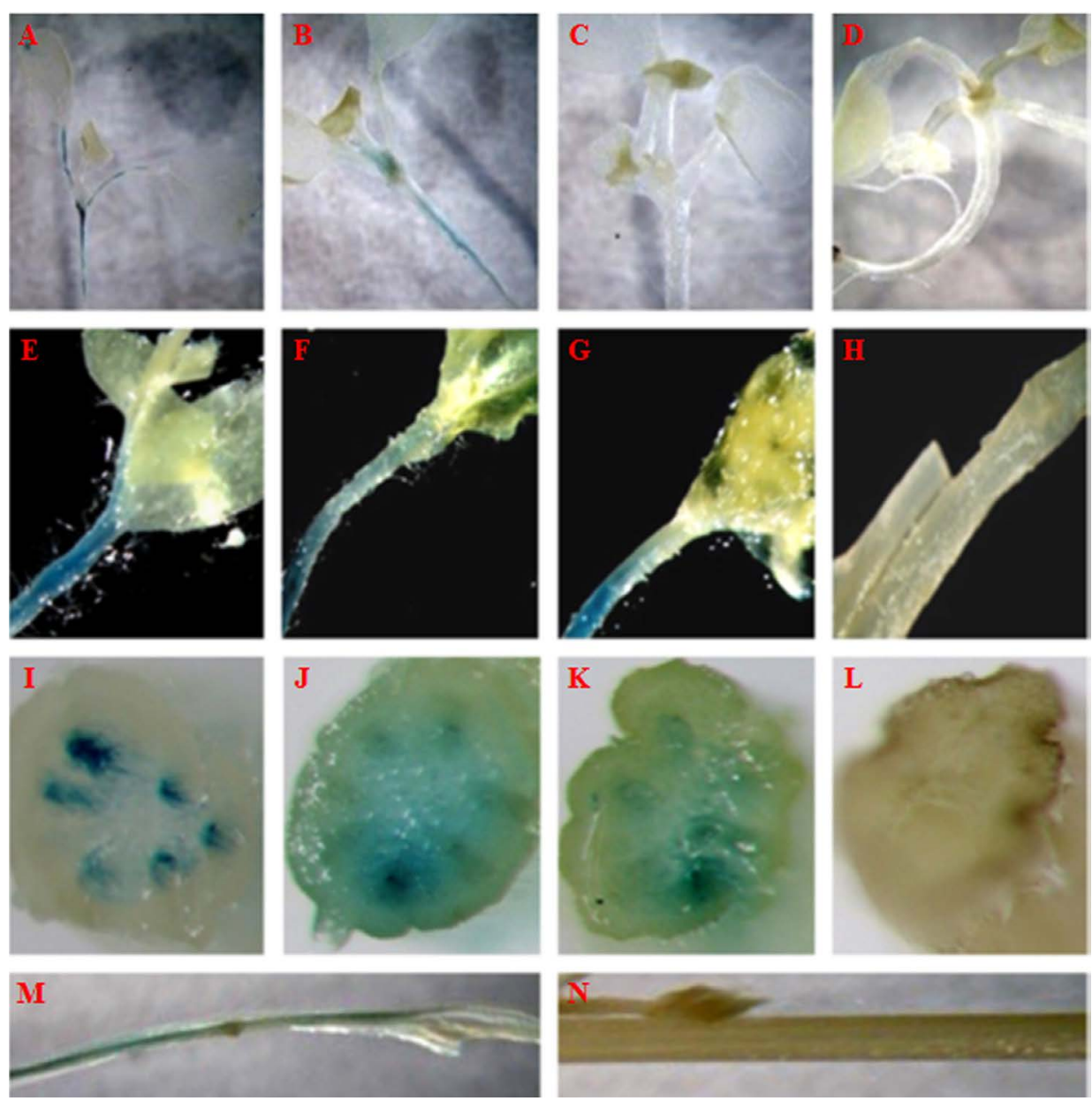

Figure 10. Histochemical Analysis of GhRING2 promoter driven GUS expression in transgenic Arabidopsis thaliana. The images (A)-(C) represent 12 day old seedlings of transgenic Arabidopsis plants containing the promoter fragments R2GUS1, R2GUS2 and R2GUS3, respectively. (D) is the wild type Arabidopsis. (E)-(G) show GUS expression in young stems of transgenic Arabidopsis thaliana plants containing the promoter fragments R2GUS1, R2GUS2 and R2GUS3, respectively. Image (D) represents the young stem of the wild type Arabidopsis thaliana. Imagines (I)-(K) represent the cross section of young stems of transgenic Arabidopsis thaliana containing the promoter fragments R2GUS1, R2GUS2 and R2GUS3, respectively. (L) represents the cross-section of mature stems of the plants containing the R2GUS1 promoter fragment. GUS expression was only detected in the young stem (image $(\mathrm{M})$ ) but not in mature stems (image $(\mathrm{N})$ ) of transgenic Arabidopsis plants containing the RGUS1 promoter fragment.

strongly agrees with the empirical data reported [41]. Similar results were reported [42], who performed RTPCR analysis of the QTL primers that are preferentially expressed between G. hirsutum Emian22 and G. barbadense 3-79 during fiber development. Expression of FPG012 primer, tightly linked with a QTL marker, reached a peak at 20 DPA in Emian 22, while the expression peak appeared at 25 DPA in 3-79. Based on the expression data between the two lines, it was suggested that the delay in gene expression may be responsible for the higher fiber strength of 3-79 than Emian 22 [42]. It is possible that the expression peak of GhRING2 in CS-B25 fiber is not at 20 DPA, but at the late secondary wall synthesis stage. Our observation suggests that the difference in GhRING2 expression between TM-1 and CS-B25 might be one of factors contributing to better fiber traits in CS-B25.

\subsection{Target Proteins and Their Functional Role}

The identification of GhRING2 target proteins, Protodermal Factor 1 (PDF1) and 7- $\beta$-like subunit of 20S pro- 
tease, allows a better understanding of the function of GhRING2 in the ubiquitin proteasome pathway and its role in cotton fiber development. GhPDF1 was reported to be one of the patterning genes and its expression reached a peak at 5-DPA in TM-1 fiber [37]. GbPDF1, a GhPDF1 homologue from G. barbadense, has been shown to be involved in cell fate determination [43]. Recently, the GbPDF1 gene had been cloned and characterized [44], and the gene had a functional role in fiber cell initiation and in the timing of fiber cell differentiation. The identification of the interaction between GhRING2 and GhPDF1 further supports that GhRING2 regulates fiber cell initiation and fiber length by targeting GhPDF1. The interaction of GhRING2 with 7- $\beta$-like subunit of 20S protease indicates that the RING-type E3 ligase could directly escort the ubiquitinated protein (such as GhPDF1) to the 20S protease via binding to the 7- $\beta$-like subunit. It is interesting to note that GbPDF1 also interacted with an ubiquitin protein PPIP1 containing an ubiquitin-like domain in the N-terminus [44].

\subsection{Promoter Activity and Expression of GhRING2}

The $E$. coli GUS ( $\beta$-glucuronidase) reporter system was used to determine the promoter activity of the GhRING2 gene in transgenic $A$. thaliana plants. Transgenic cotton plants were not used for promoter analysis due to the low efficiency of cotton transformation. In addition, relatively longer time is required for the regeneration and growth of cotton plants [32]. The promoters R2GUS1 and R2GUS2, located from nt -607 to -1506 , directed GUS expression in the hypocotyl and apical ends of the cotyledons in transgenic Arabidopsis seedlings. Albornos et al. [45] reported that Arabidopsis AtBGAL12 ( $\beta$-galactosidase gene) promoter directed a similar GUS expression in the root, hypocotyl and apical end of the cotyledons of transgenic Arabidopsis plants. They proposed that AtBGAL12 along with expansions were participating in cell wall extension or remodelling [45]. The hypocotyl cells may correspond to rapidly elongating cells, and the apical end cells of the cotyledons may represent cotyledon forming cells [45]. GhRING2 may be involved in cell wall remodeling, and in coordination with expansins it may play a functional role in cotton fiber cell elongation. The GUS activity was observed in young stems of mature transgenic Arabidopsis plants for all three GhRING2 promoter fragments, which conflicts with the previous observation that the GUS activity was detected in transgenic Arabidopsis seedlings only containing R2GUS1 and R2GUS2 promoter fragments. This may be due to the fact that the GhRING2 promoter region has more than one transcription factor binding site; one being present in the R2GUS3 promoter fragment and the other located between -607 to -1506 nt. The GhRING2 gene may be regulated by more than one transcriptional factor (TF) that is expressed temporally at different stages of plant development. For instance, one TF may be expressed in the seedling stage and the other during the development of young stems in transgenic Arabidopsisplants. The GUS activity of the GhRING2 promoter was localized to xylem and cambium cells of young stems only and not in mature stems of transgenic Arabidopsis thaliana plants. Persson et al. [46] studied the expression of an Arabidopsis IRX8 gene encoding glycosyltransferase and found that the gene was essential for secondary wall formation. The IRX8 gene promoter directed GUS expression in developing fiber and young xylem cells where secondary cell walls are deposited. The IRX8 mutant plants had reduced levels of glycan and homogalacturonan, collapsed xylem vessels and displayed a dwarfed phenotype [46]. The observation of GUS expression in xylem cells of transgenic Arabidopsis plants containing the GhRING2 promoter suggests that the GhRING2 gene may be involved in cotton fiber secondary cell wall thickening.

\section{Acknowledgements}

This study was supported by Special Research Initiative (SRI) grants from Mississippi Agricultural and Forestry Experiment Station (MAFES), approved for publication as Journal Article No. J-12579 of the Mississippi Agricultural and Forestry Experiment Station, Mississippi State University.

\section{References}

[1] Graves, D. and Stewart, J. (1988) Chronology of the Differentiation of Cotton (Gossypium hirsutum L.) Fiber Cells. Planta, 175, 254-258. http://dx.doi.org/10.1007/BF00392435

[2] Meinert, M.C. and Delmer, D.P. (1977) Changes in Biochemical Composition of the Cell Wall of the Cotton Fiber during Development. Plant Physiology, 59, 1088-1097. http://dx.doi.org/10.1104/pp.59.6.1088

[3] Haigler, C.H., Singh, B., Wang, G. and Zhang, D. (2009) Genomics of Cotton Fiber Secondary Wall Deposition and Cellulose Biogenesis. Genetics and Genomics of Cotton, 3, 385-417. http://dx.doi.org/10.1007/978-0-387-70810-2_16

[4] Vierstra, R.D. (2009) The Ubiquitin-26S Proteasome System at the Nexus of Plant Biology. Nature Reviews Molecular 
Cell Biology, 10, 385-397. http://dx.doi.org/10.1038/nrm2688

[5] Liu, H. and Stone, S.L. (2011) E3 Ubiquitin Ligases and Abscisic Acid Signaling. Plant Signaling and Behavior, 6, 344-348. http://dx.doi.org/10.4161/psb.6.3.13914

[6] Lyzenga, W.J., Booth, J.K. and Stone, S.L. (2012) The Arabidopsis RING-Type E3 Ligase XBAT32 Mediates the Proteasomal Degradation of the Ethylene Biosynthetic Enzyme, 1-Aminocyclopropane-1-Carboxylate Synthase 7. Plant Journal, 71, 23-34. http://dx.doi.org/10.1111/j.1365-313X.2012.04965.x

[7] Santner, A. and Estelle, M. (2010) The Ubiquitin-Proteasome Growth and Development by Promoting Protein Death. Plant Journal, 61, 1029-1040. http://dx.doi.org/10.1111/j.1365-313X.2010.04112.x

[8] Stone, S.L. and Callis, J. (2007) Ubiquitin Ligases Mediate Growth and Development by Promoting Protein Death. Current Opinion in Plant Biology, 10, 624-632. http://dx.doi.org/10.1016/j.pbi.2007.07.010

[9] Tan, X. and Zheng, N. (2009) Hormone Signaling through Protein Destruction: A Lesson from Plants. American Journal of Physiol-Endocrinology and Metabolism, 296, E223-E227. http://dx.doi.org/10.1152/ajpendo.90807.2008

[10] Tang, W., Yuan, M., Wang, R., Yang, Y., Wang, C., Oses-Prieto, J.A., Kim, T.-W., Zhou, H.-W., Deng, Z. and Gampala, S.S. (2011) PP2A Activates Brassinosteroid-Responsive Gene Expression and Plant Growth by Dephosphorylating BZR1. Nature Cell Biology, 13, 124-131. http://dx.doi.org/10.1038/ncb2151

[11] Liu, D., Tu, L., Wang, L., Li, Y., Zhu, L. and Zhang, X. (2008) Characterization and Expression of Plasma and Tonoplast Membrane Aquaporins in Elongating Cotton Fibers. Plant Cell Reports, 27, 1385-1394. http://dx.doi.org/10.1007/s00299-008-0545-6

[12] Seo, P.J., Jung, J.H., Park, M.J., Lee, K. and Park, C.M. (2013) Controlled Turnover of CONSTANS Protein by the HOS1 E3 Ligase Regulates Floral Transition at Low Temperatures. Plant Signaling and Behavior, 8, e23780. http://dx.doi.org/10.4161/psb.23780

[13] Moon, J., Parry, G. and Estelle, M. (2004) The Ubiquitin-Proteasome Pathway and Plant Development. Plant Cell, 16, 3181-3195. http://dx.doi.org/10.1105/tpc.104.161220

[14] Bae, H., Kim, S.K., Cho, S.K., Kang, B.G. and Kim, W.T. (2011) Overexpression of OsRDCP1, a Rice RING Domain-Containing E3 Ubiquitin Ligase, Increased Tolerance to Drought Stress in Rice (Oryza sativa L.). Plant Science, 180, 775-782. http://dx.doi.org/10.1016/j.plantsci.2011.02.008

[15] Cheng, M.C., Hsieh, E.J., Chen, J.H., Chen, H.Y. and Lin, T.P. (2012) Arabidopsis RGLG2, Functioning as a RING E3 Ligase, Interacts with AtERF53 and Negatively Regulates the Plant Drought Stress Response. Plant Physiology, 158, 363-375. http://dx.doi.org/10.1104/pp.111.189738

[16] Qin, Y.M., Hu, C.Y., Pang, Y., Kastaniotis, A.J., Hiltunen, J.K. and Zhu, Y.X. (2007) Saturated Very-Long-Chain Fatty Acids Promote Cotton Fiber and Arabidopsis Cell Elongation by Activating Ethylene Biosynthesis. The Plant Cell, 19, 3692-3704. http://dx.doi.org/10.1105/tpc.107.054437

[17] Tang, N., Zhang, H., Li, X., Xiao, J. and Xiong, L. (2012) Constitutive Activation of Transcription Factor OsbZIP46 Improves Drought Tolerance in Rice. Plant Physiology, 158, 1755-1768. http://dx.doi.org/10.1104/pp.111.190389

[18] Zhang, Y., Wen, P., Lau, O.S. and Deng, X.W. (2007) Characterization of the Ubiquitin E2 Enzyme Variant Gene Family in Arabidopsis. Journal of Integrative Plant Biology, 49, 120-126. http://dx.doi.org/10.1111/j.1744-7909.2006.00419.x

[19] Pickart, C.M. (2001) Mechanisms Underlying Ubiquitination. Annual Review of Biochemistry, 70, 503-533. http://dx.doi.org/10.1146/annurev.biochem.70.1.503

[20] Zhang, X.D., Jenkins, J.N., Callahan, F.E., Creech, R.G., Si, Y., McCarty, J.C., Saha, S. and Ma, D.P. (2003) Molecular Cloning, Differential Expression, and Functional Characterization of a Family of Class I Ubiquitin-Conjugating Enzyme (E2) Genes in Cotton (Gossypium). Biochimica et Biophysica Acta (BBA), Gene Structure and Expression, 1625, 269-279. http://dx.doi.org/10.1016/S0167-4781(02)00623-1

[21] Ho, M.H., Saha, S., Jenkins, J.N. and Ma, D.P. (2010) Characterization and Promoter Analysis of a Cotton RING-Type Ubiquitin Ligase (E3) Gene. Molecular Biotechnology, 46, 140-148. http://dx.doi.org/10.1007/s12033-010-9280-7

[22] Wu, J., Jenkins, J.N., McCarty, J.C., Wu, J., Saha, S. and Stelly, D.M. (2006) An Additive-Dominance Model to Determine Chromosomal Effects in Chromosome Substitution Lines and Other Germplasms. Theoretical and Applied Genetics, 112, 391-399. http://dx.doi.org/10.1007/s00122-005-0042-z

[23] Saha, S., Jenkins, J.N., Wu, J., McCarty, J.C., Gutiérrez, O.A., Percy, R.G., Cantrell, R.G. and Stelly, D.M. (2006) Effects of Chromosome-Specific Introgression in Upland Cotton on Fiber and Agronomic Traits. Genetics, 172, 19271938. http://dx.doi.org/10.1534/genetics.105.053371

[24] Bandi, S. (2011) Identification of Genes Differentially Expressed in Elongating Fiber in a Cotton Chromosome Substitution Line CS-B25. M.Sc. Thesis, Mississippi State University, Starkville.

[25] Triglia, T., Peterson, M.G. and Kemp, D.J. (1988) A Procedure for in Vitro Amplification of DNA Segments That Lie 
Outside the Boundaries of Known Sequences. Nucleic Acids Research, 16, 8186. http://dx.doi.org/10.1093/nar/16.16.8186

[26] Eswar, N., Webb, B., Renom, M.A.M., Madhusudhan, M., Eramian, D., Shen, M., Pieper, U. and Sali, A. (2006) Comparative Protein Structure Modeling Using MODELLER. Current Protocols in Bioinformatics, 5, 1-30.

[27] Sanner, M.F. (1999) Python: A Programming Language for Software Integration and Development. Journal of Molecular Graphics and Modelling, 17, 57-61.

[28] Katoh, S., Hong, C., Tsunoda, Y., Murata, K., Takai, R., Minami, E., Yamazaki, T. and Katoh, E. (2003) High Precision NMR Structure and Function of the RING-H2 Finger Domain of EL5, a Rice Protein Whose Expression Is Increased upon Exposure to Pathogen-Derived Oligosaccharides. Journal of Biological Chemistry, 278, 15341-15348. http://dx.doi.org/10.1074/jbc.M210531200

[29] Wan, C.Y. and Wilkins, T.A. (1994) A Modified Hot Borate Method Significantly Enhances the Yield of High-Quality RNA from Cotton (Gossypium hirsutum L.). Analytical Biochemistry, 223, 7-12. http://dx.doi.org/10.1006/abio.1994.1538

[30] Walkerpeach, C.R. and Velten, J. (1994) Agrobacterium-Mediated Gene Transfer to Plant Cells: Cointegrate and Binary Vectors Systems. In: Gelvin, S.B. and Schilperoort, R.A., Eds., Plant Molecular Biology Manual, Springer Netherlands, 33-51.

[31] Clough, S.J. and Bent, A.F. (1998) Floral Dip: A Simplified Method for Agrobacterium-Mediated Transformation of Arabidopsis thaliana. The Plant Journal, 16, 735-743. http://dx.doi.org/10.1046/j.1365-313x.1998.00343.x

[32] Sessions, A., Weigel, D. and Yanofsky, M.F. (1999) The Arabidopsis thaliana MERISTEM LAYER 1 Promoter Specifies Epidermal Expression in Meristems and Young Primordia. The Plant Journal, 20, 259-263. http://dx.doi.org/10.1046/j.1365-313x.1999.00594.x

[33] Gietz, R.D., Schiestl, R.H., Willems, A.R. and Woods, R.A. (1995) Studies on the Transformation of Intact Yeast Cells by the LiAc/SS-DNA/PEG Procedure. Yeast, 11, 355-360. http://dx.doi.org/10.1002/yea.320110408

[34] Kraft, E.A. (2007) An Investigation of the Ubiquitin Conjugating Enzymes and RING E3 Ligases in Arabidopsis thaliana. Ph.D. Dissertation, University of California, Oakland.

[35] Gasteiger, E., Hoogland, C., Gattiker, A., Duvaud, S., Wilkins, M.R., Appel, R.D. and Bairoch, A. (2005) Protein Identification and Analysis Tools on the ExPASy Server. In: Walker, J.M., Ed., The Proteomics Protocols Handbook, Humana Press, Totowa, 571-607. http://dx.doi.org/10.1385/1-59259-890-0:571

[36] Breton, G., Danyluk, J., Charron, J.B. and Sarhan, F. (2003) Expression Profiling and Bioinformatic Analyses of a Novel Stress-Regulated Multispanning Transmembrane Protein Family from Cereals and Arabidopsis. Plant Physiology, 132, 64-74. http://dx.doi.org/10.1104/pp.102.015255

[37] Lee, J.J., Hassan, O.S., Gao, W., Wei, N.E., Kohel, R.J., Chen, X.Y., Payton, P., Sze, S.H., Stelly, D.M. and Chen, Z.J. (2006) Developmental and Gene Expression Analyses of a Cotton Naked Seed Mutant. Planta, 223, 418-432. http://dx.doi.org/10.1007/s00425-005-0098-7

[38] Hovav, R., Udall, J.A., Hovav, E., Rapp, R., Flagel, L. and Wendel, J.F. (2008) A Majority of Cotton Genes Are Expressed in Single-Celled Fiber. Planta, 227, 319-329. http://dx.doi.org/10.1007/s00425-007-0619-7

[39] Al-Ghazi, Y., Bourot, S., Arioli, T., Dennis, E.S. and Llewellyn, D.J. (2009) Transcript Profiling during Fiber Development Identifies Pathways in Secondary Metabolism and Cell Wall Structure That May Contribute to Cotton Fiber Quality. Plant Cell Physiology, 50, 1364-1381. http://dx.doi.org/10.1093/pcp/pcp084

[40] Applequist, W.L., Cronn, R. and Wendel, J.F. (2001) Comparative Development of Fiber in Wild and Cultivated Cotton. Evolution and Development, 3, 3-17. http://dx.doi.org/10.1046/j.1525-142x.2001.00079.x

[41] Saha, S., Wu, J., Jenkins, J.N., McCarty, Jr, J.C., Gutierrez, O.A., Stelly, D.M., Percy, R.G. and Raska, D.A. (2004) Effect of Chromosome Substitutions from Gossypium barbadense L. 3-79 into G. hirsutum L. TM-1 on Agronomic and Fiber Traits. Journal of Cotton Science, 8, 162-169.

[42] Li, X., Yuan, D., Zhang, J., Lin, Z. and Zhang, X. (2013) Genetic Mapping and Characteristics of Genes Specifically or Preferentially Expressed during Fiber Development in Cotton. PloS ONE, 8, e54444. http://dx.doi.org/10.1371/journal.pone.0054444

[43] Tu, L., Zhang, X.L., Liang, S.G., Liu, D.Q., Zhu, L.F., Zeng, F.C., Nie, Y.C., Guo, X.P., Deng, F.L., Tan, J.F. and Xu, L. (2007) Genes Expression Analyses of Sea-Island Cotton (Gossypium barbadense L.) during Fiber Development. Plant Cell Reporter, 26, 1309-1320. http://dx.doi.org/10.1007/s00299-007-0337-4

[44] Deng, F., Tu, L., Tan, J., Li, Y., Nie, Y. and Zhang, X. (2012) GbPDF1 Is Involved in Cotton Fiber Initiation via the Core Cis-Element HDZIP2ATATHB2. Plant Physiology, 158, 890-904. http://dx.doi.org/10.1104/pp.111.186742

[45] Albornos, L., Ignacio, M., Pérez, P., Marcos, R., Dopico, B. and Labrador, E. (2012) Promoter Activities of Genes Encoding $\beta$-Galactosidases from Arabidopsis a1 Subfamily. Plant Physiology and Biochemistry, 60, 223-232. 
http://dx.doi.org/10.1016/j.plaphy.2012.08.012

[46] Persson, S., Caffall, K.H., Freshour, G., Hilley, M.T., Bauer, S., Poindexter, P., Hahn, M.G., Mohnen, D. and Somerville, C. (2007) The Arabidopsis Irregular Xylem8 Mutant Is Deficient in Glucuronoxylan and Homogalacturonan, Which Are Essential for Secondary Cell Wall Integrity. The Plant Cell, 19, 237-255.

http://dx.doi.org/10.1105/tpc.106.047720

[47] Saitou, N. and Nei, M. (1987) The Neighbor-Joining Method: A New Method for Reconstructing Phylogenetic Trees. Molecular Biology and Evolution, 4, 406-425.

[48] Thompson, J.D., Gibson, T.J., Plewniak, F., Jeanmougin, F. and Higgins, D.G. (1997) The CLUSTAL_X Windows Interface: Flexible Strategies for Multiple Sequence Alignment Aided by Quality Analysis Tools. Nucleic Acids Research, 25, 4876-4882. http://dx.doi.org/10.1093/nar/25.24.4876

[49] Tamura, K., Peterson, D., Peterson, N., Stecher, G., Nei, M.A. and Kumar, S. (2011) MEGA5: Molecular Evolutionary Genetics Analysis Using Maximum Likelihood, Evolutionary Distance, and Maximum Parsimony Methods. Molecular Biology and Evolution, 28, 2731-2739. http://dx.doi.org/10.1093/molbev/msr121 
Scientific Research Publishing (SCIRP) is one of the largest Open Access journal publishers. It is currently publishing more than 200 open access, online, peer-reviewed journals covering a wide range of academic disciplines. SCIRP serves the worldwide academic communities and contributes to the progress and application of science with its publication.

Other selected journals from SCIRP are listed as below. Submit your manuscript to us via either submit@scirp.org or Online Submission Portal.
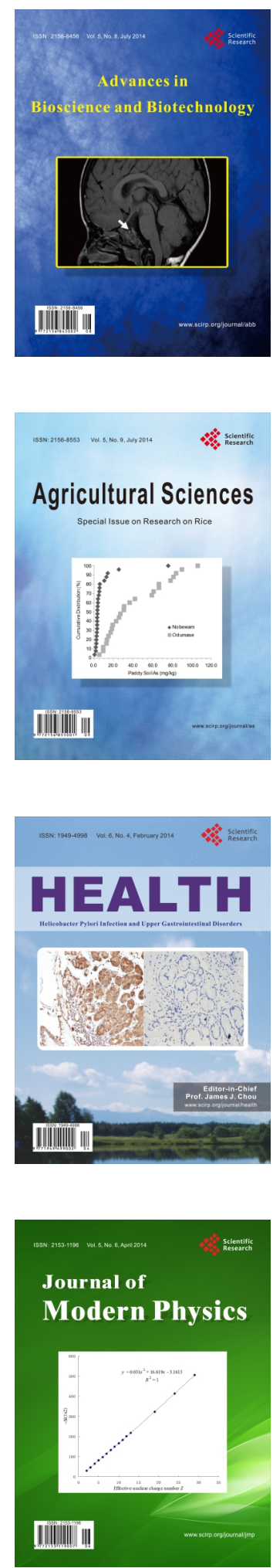
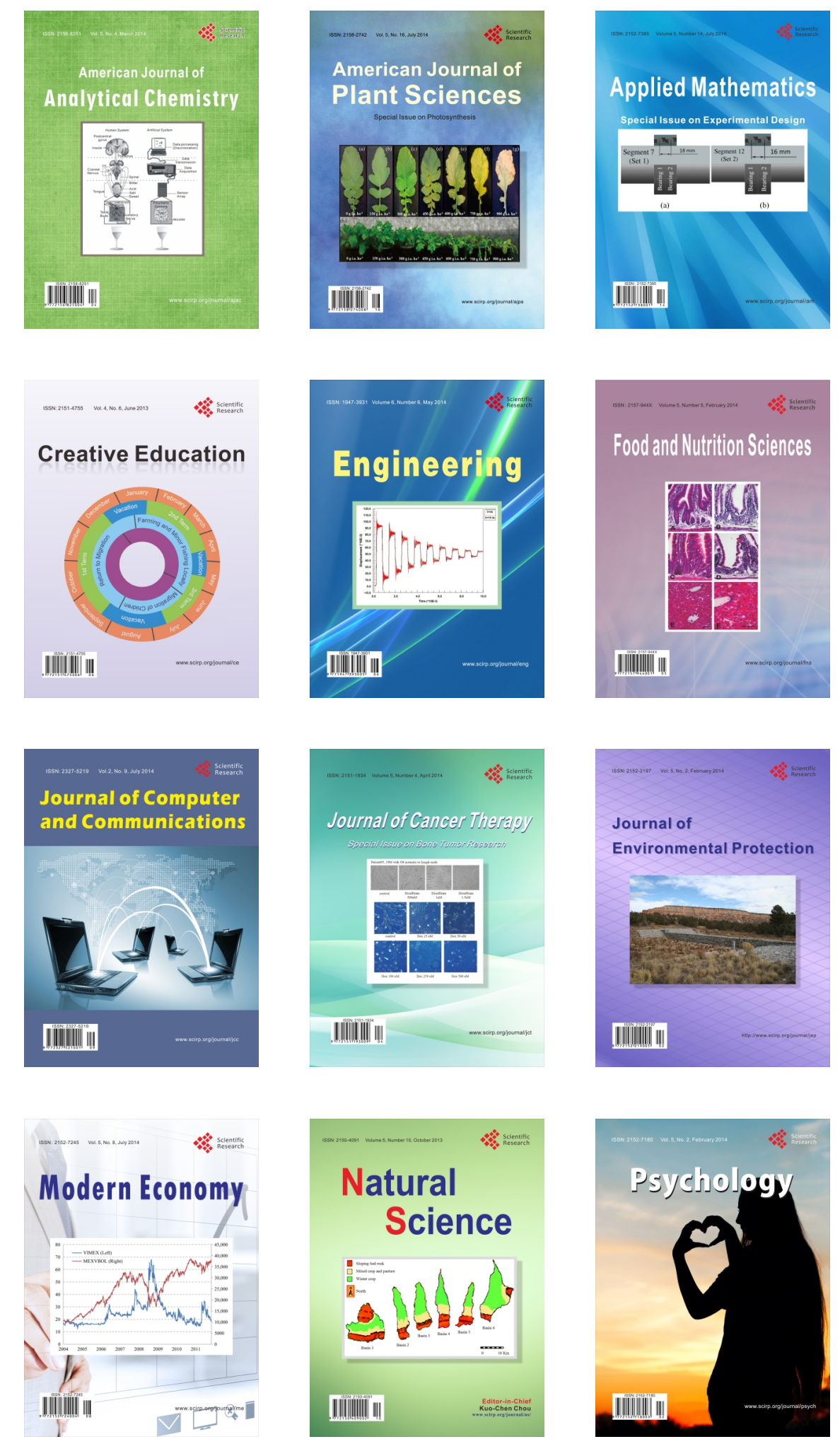